\title{
Vascular $\beta$-amyloid and early astrocyte alterations impair cerebrovascular function and cerebral metabolism in transgenic $\operatorname{arcA\beta }$ mice
}

\author{
Mario Merlini - Eric P. Meyer • \\ Alexandra Ulmann-Schuler $\cdot$ Roger M. Nitsch
}

Received: 10 December 2010/Revised: 11 April 2011 / Accepted: 4 May 2011 / Published online: 19 June 2011

(C) The Author(s) 2011. This article is published with open access at Springerlink.com

\begin{abstract}
Cerebrovascular lesions related to congophilic amyloid angiopathy (CAA) often accompany deposition of $\beta$-amyloid $(A \beta)$ in Alzheimer's disease (AD), leading to disturbed cerebral blood flow and cognitive dysfunction, posing the question how cerebrovascular pathology contributes to the pathology of AD. To address this question, we characterised the morphology, biochemistry and functionality of brain blood vessels in transgenic arctic $\beta$-amyloid $(\operatorname{arc} \mathrm{A} \beta)$ mice expressing human amyloid precursor protein (APP) with both the familial AD-causing Swedish and Arctic mutations; these mice are characterised by strong CAA pathology. Mice were analysed at early, mid and late-stage pathology. Expression of the glucose transporter GLUT1 at the blood-brain barrier (BBB) was significantly decreased and paralleled by impaired in vivo blood-to-brain glucose transport and reduced cerebral lactate release during neuronal activation from mid-stage pathology onwards. Reductions in astrocytic GLUT1 and lactate transporters, as well as retraction of astrocyte endfeet and swelling consistent with neurovascular uncoupling, preceded wide-spread $\beta$-amyloid plaque pathology. We
\end{abstract}

M. Merlini $(\bowtie) \cdot$ R. M. Nitsch $(\bowtie)$

Division of Psychiatry Research, University of Zürich,

August Forel-Strasse 1, 8008 Zurich, Switzerland

e-mail: mario.merlini@gladstone.ucsf.edu

R. M. Nitsch

e-mail: nitsch@bli.uzh.ch

E. P. Meyer - A. Ulmann-Schuler

Institute of Molecular Life Sciences, University of Zürich,

Winterthurerstrasse 190, 8057 Zurich, Switzerland

Present Address:

M. Merlini

Gladstone Institute of Neurological Disease,

1650 Owens Street, San Francisco, CA 94158, USA show that CAA at later disease stages is accompanied by severe morphological alterations of brain blood vessels including stenoses, BBB leakages and the loss of vascular smooth muscle cells (SMCs). Together, our data establish that cerebrovascular and astrocytic pathology are paralleled by impaired cerebral metabolism in $\operatorname{arc} \mathrm{A} \beta$ mice, and that astrocyte alterations occur already at premature stages of pathology, suggesting that astrocyte dysfunction can contribute to early behavioural and cognitive impairments seen in these mice.

Keywords Alzheimer's disease .

Congophilic amyloid angiopathy .

Cerebral glucose metabolism · Astrocytes

\section{Introduction}

Vascular accumulation of $\beta$-amyloid (A $\beta)$ results in congophilic amyloid angiopathy (CAA), a vascular lesion diagnosed as part of $\beta$-amyloid pathology in up to $90 \%$ of post-mortem brains with a neuropathological diagnosis of Alzheimer's disease (AD) [57]. CAA is associated with a plethora of abnormalities and malfunctioning of the cerebrovasculature $[6,15,40,49,52,64]$ including ruptures of the vessel walls causing microhaemorrhages and lesions of the blood-brain barrier (BBB), resulting in inflammation, vascular oedema and uncontrolled influx of peripheral blood components into the brain parenchyma [65]. As a result of CAA, vascular basement membranes (VBM) thicken and smooth muscle cells (SMC) degenerate, jointly leading to impaired cerebral blood flow (CBF) $[15,18,40]$. Physiological functions of the cerebral vasculature are compromised early, possibly even preceding the onset of $\mathrm{AD}$ pathology including the onset of $\mathrm{CAA}$, and raising the 
possibility of an early involvement of vascular dysfunction in the pathophysiology of the disease with disturbances in angiogenesis [11, 54]. Cerebral hypoperfusion and hypometabolism occur in patients with mild cognitive impairment (MCI), and were also observed in transgenic mouse models of $\mathrm{AD}$ in which they precede the onset of $\beta$-amyloid plaque pathology $[5,10]$. While vascular and metabolic disorders including atherosclerosis and diabetes can strongly impair cerebral circulation [25], neurotoxic soluble $A \beta$ species can also diminish performance of the cerebral vasculature $[16,18]$, presumably already at early and pre-pathological stages of $\beta$-amyloid pathology. As a consequence, $A \beta$-related disruption of brain blood flow could lead to neuronal impairments by compromising a steady vascular supply of essential metabolic precursors such as oxygen, amino acids and glucose [4, 24, 65], as well as by decreasing cerebral lymphatic drainage of metabolic products $[58,59]$. Astrocytes play a pivotal role in regulating these functions by mediating signalling and nutrient exchange between neurons and vascular endothelium $[1,23]$ via astrocyte endfeet that contain numerous nutrient transporters including the glucose transporter GLUT1 and the monocarboxylate transporter 1 (MCT1), in addition to many receptors essential for signal transduction $[1,41]$. Interactions of astrocyte endfeet with the VBM are mediated via the dystroglycan protein complex that binds to laminin and neuronal-expressed neurexin [2, 56, 63]. Astrocyte endfeet can retract and swell during pathological conditions including neuroinflammation in multiple sclerosis and in experimental autoimmune encephalomyelitis [63]. Because both astrogliosis surrounding $\beta$-amyloid plaques and neuroinflammation occur in $\mathrm{AD}$, alterations in astrocyte endfeet structure and function are likely to be present $[13,63,64]$; such changes consistent with loss of contact between astrocyte endfeet and the cerebrovasculature were indeed observed in a transgenic mouse model of $\mathrm{AD}$ [61]. To further understand the role of the cerebrovasculature and astrocytes as well as their influence on cerebral metabolism in $\beta$-amyloid pathology, we characterised cerebral blood vessels and astrocytes in transgenic $\operatorname{arcA} \beta$ mice expressing both the Swedish and Arctic APP mutations. This mouse model exhibits severe vascular AD pathology with significant electrophysiological and behavioural deficits preceding $\beta$-amyloid deposition [28, 35]. The Swedish double mutation (K670N and M671L) together with the arctic mutation (E693G) leads to an over-production of aggregation-prone $A \beta_{42}$ and accumulation of $\mathrm{A} \beta$ at brain blood vessels [28, 35]. Similar as was described for other mouse models of $\mathrm{AD}[22,42,55$, 62], our studies identified severe morphological and biochemical abnormalities of CAA-affected vessels including stenoses, leakages, loss of vascular smooth muscle cells, and decreased GLUT1 expression. We also observed a unique astrocytic pathology commencing at the early disease stages. These included reduced GLUT1 and MCT1 expression, decreased astrocytic release of lactate in vivo and ex vivo, increased laminin secretion and retraction and swelling of astrocyte endfeet surrounding diffuse and vascular $A \beta$ depositions, signs of neurovascular uncoupling and BBB disruption. In vivo microdialysis revealed severe reductions in brain glucose concentrations at baseline during neuronal stimulation and impaired blood-to-brain glucose uptake. These findings establish an astrocytic involvement in the early stages of the cerebrovascular and metabolic pathology in this transgenic mouse model of $\mathrm{AD}$.

\section{Materials and methods}

Animals

$\operatorname{ArcA} \beta$ mice were produced as described previously by Knobloch and colleagues [28]. Non-transgenic littermates were used as controls when specified. All animals were housed 3-5 per cage and had access to food and water ad libitum under a 12-h light/dark cycle. All in vivo experiments conducted complied with Swiss federal and cantonal law and were performed with the approval of the Swiss Veterinary Council, approval number 47/2008, 3781.

\section{Classification of disease pathology}

Transgenic $\operatorname{arc} \mathrm{A} \beta$ mice were grouped according to the disease pathology in the following groups: early-stage pathology: 6 months old, mid-stage pathology: 9-13 months old and late-stage disease pathology: 16-22 months old. Disease stage pathology was based on overall cerebral $A \beta$ plaque burden including CAA and cognitive performance according to Knobloch et al. [28].

\section{Perfusion of mice and collection of brain material}

Mice were deeply anaesthetised using a cocktail of $1.25 \%$ ketamine and $0.25 \%$ xylazine. Mice used for histochemistry purposes were transcardially perfused with ice-cold PBS $\left(10 \mathrm{mM} \quad \mathrm{Na}_{2} \mathrm{HPO}_{4}, 2.5 \mathrm{mM} \quad \mathrm{NaH}_{2} \mathrm{PO}_{4}, 150 \mathrm{mM}\right.$ $\mathrm{NaCl}, 3 \mathrm{mM} \mathrm{KCl}$ ) followed by ice-cold paraformaldehyde (PFA) $4.0 \%$ in phosphate buffer $0.15 \mathrm{M}\left(\mathrm{Na} 2 \mathrm{HPO}_{4}+\right.$ $\mathrm{NaH}_{2} \mathrm{PO}_{4}$ in double-distilled water), $\mathrm{pH}$ 7.4. Brains were incubated in PFA $4.0 \%$ in PBS for $4 \mathrm{~h}$ at $4^{\circ} \mathrm{C}$ followed by incubation in sucrose $30 \%$ in PBS for $24-36 \mathrm{~h}$. Mice serving biochemistry purposes were transcardially perfused with ice-cold PBS only. Hippocampi were dissected out and cortices, hippocampi and cerebella were separately snap-frozen in liquid nitrogen and stored at $-80^{\circ} \mathrm{C}$. 
Vascular corrosion casts and scanning electron microscopy

All procedures were carried out as described previously [34]. In brief, anaesthetised mice (100 mg/kg pentobarbital) were first perfused with artificial cerebrospinal fluid (aCSF) containing heparin followed by a perfusion with $4 \%$ PFA in PBS. Subsequently, mice were perfused with the casting resin PU4ii (vasQtec, Switzerland). After a curing period of 7 days, soft tissue was macerated in $7.5 \%$ potassium hydroxide at $50^{\circ} \mathrm{C}$ for 24-72 $\mathrm{h}$ and the bones decalcified in $5 \%$ formic acid at $50^{\circ} \mathrm{C}$ for 24-72 h. Vascular corrosion casts were washed with water, dried by lyophilisation and sputter-coated with gold particles for scanning electron microscopy (SEM) purposes.

Extraction of membrane brain proteins

Working on ice, brain materials (hippocampi and cortices) were homogenised separately in homogenisation buffer [Tris- $\mathrm{HCl} 10 \mathrm{mM}$, pH 7.4, EDTA $1.0 \mathrm{mM}$, sucrose $250 \mathrm{mM}$ and protease inhibitors (Complete ${ }^{\circledR}$, Roche, Switzerland)] with 30 strokes using a glass Dounce homogeniser with Teflon pestle (Wheaton, USA). Homogenates were centrifuged at $900 \times g$ and $4^{\circ} \mathrm{C}$ for $10 \mathrm{~min}$. The formed supernatants were subsequently centrifuged at $110,000 \times g$ and $4^{\circ} \mathrm{C}$ for 75 min. Supernatants were discarded and the pellets dissolved in solubilisation buffer [Tris- $\mathrm{HCl} 10 \mathrm{mM}, \mathrm{pH} 7.4$, EDTA $1.0 \mathrm{mM}$, Triton X-100 0.50\%, sodium deoxycholate $0.50 \%$ and protease inhibitors (Complete ${ }^{\circledR}$, Roche, Switzerland)] by continuous rotation at $4^{\circ} \mathrm{C}$ for $1 \mathrm{~h}$. The dissolved pellets were centrifuged at $14,000 \times g$ and $4^{\circ} \mathrm{C}$ for $10 \mathrm{~min}$. Supernatants were collected and protein concentrations measured using the Pierce ${ }^{\circledR}$ BCA Protein Assay Kit (Thermo Scientific, Rockford, IL, USA).

\section{Immunoblotting}

Equal amounts of total protein or equal volumes of cell culture media were subjected to separation on 10-20\% Tricine gels (Invitrogen, Basel, Switzerland), blotted on nitrocellulose membranes Immobilon-P PVDF membranes $(0.45 \mu \mathrm{m}$, Millipore, Switzerland). The immunoblot was then incubated with primary antibodies followed by incubation with HRPtagged secondary antibodies. Detection was performed using chemiluminescence visualised using ECL WB reagents (Amersham Pharmacia, GE, Germany) or SuperSignal West Dura Extended Duration reagents (Pierce, Rockford, IL, USA) on BIOMAX films (GE, Germany).

\section{Immunohistochemistry}

Paraformaldehyde-fixed and cryoprotected brains were cut into $30 \mu \mathrm{m}$ thick slices at $\sim-80^{\circ} \mathrm{C}$ using a microtome (Leica
Jung HN40) and kept at $-20^{\circ} \mathrm{C}$ in an anti-freeze solution (phosphate buffer $0.50 \mathrm{M}$ in MilliQ water:ethyleneglycol:glycerol $=1.3: 1: 1$ ) until staining was performed. All immunohistochemical stainings were executed using the free-floating method. Washing steps were carried out between all incubations using washing buffer (TBS pH 7.4 containing $0.2 \%$ Triton X-100) at RT. Antigen retrieval was performed when required using the proteinase $\mathrm{K}$ antigen retrieval method [incubation of sections in proteinase $K$ solution (proteinase $\mathrm{K} 20 \mu \mathrm{g} / \mathrm{ml}$ in Tris base $50 \mathrm{mM}+$ EDTA $1.0 \mathrm{mM}, \mathrm{pH} 8.0)]$ at $37^{\circ} \mathrm{C}$ for $7 \mathrm{~min}$. Slices were blocked for $1 \mathrm{~h}$ at RT using blocking buffer (5.0\% goat serum $5.0 \%$ donkey serum in washing buffer). Blocked slices were incubated overnight at $4^{\circ} \mathrm{C}$ with slight agitation in primary antibody incubation buffer $(2.5 \%$ goat serum and $2.5 \%$ donkey serum in washing buffer) containing the primary antibody/antibodies. Subsequently, secondary antibody incubations were carried out for $2 \mathrm{~h}$ at RT. Slices were washed in washing buffer, mounted on chrom-gelatin-coated microscopy slides (SuperFrost Plus, Menzel, Braunschweig, Germany) and glass-covered using Hydromount ${ }^{\circledR}$ (National Diagnostics, Hull, UK).

\section{Image analysis}

Fluorescent immunohistochemical images were acquired on a Leica DM4000B microscope using an Olympus DP71 colour digital camera and newCAST software (Visiopharm, Copenhagen, Denmark). Image analysis was carried out with ImageJ software (NIH, USA).

High-resolution imaging was performed using a TCS/SP2 Leica confocal laser scanning microscope (Leica, Wetzlar, Germany) with $63 \times$ objective (water, NA: 1.2) where mentioned in the figure legends. All confocal images are maximal intensity projections of $z$ stacks composed of multiple images.

Trypan Blue BBB leakage experiments

Mice received an intraperitoneal injection of $200 \mu \mathrm{l}$ of a $0.4 \%$ Trypan Blue solution in $0.85 \%$ saline (Gibco, Switzerland). Thirty minutes after Trypan Blue administration, mice were perfused and their brains processed for histological analysis as described above. Trypan Blue was visualised using immunofluorescence with excitation and emission wavelengths at 642 and $660 \mathrm{~nm}$, respectively. Protocol adapted from Persson et al. [39].

Prussian Blue and Thioflavin S stain for detection of haemorrhages and CAA

Haemorrhages were visualised using the Prussian Blue stain method on free-floating brain sections. Free-floating brain sections were incubated in a mixture of equal 
volumes of $10 \%$ potassium ferrocyanide $\left(\mathrm{K}_{4} \mathrm{Fe}(\mathrm{CN})_{6}\right.$ trihydrate) in d.d. $\mathrm{H}_{2} \mathrm{O}$ and $20 \%$ hydrochloric acid $(\mathrm{HCl})$ in d.d. $\mathrm{H}_{2} \mathrm{O}$ for $30 \mathrm{~min}$. Brain sections were subsequently washed with d.d. $\mathrm{H}_{2} \mathrm{O}$, counterstained with nuclear fast red solution for $10 \mathrm{~min}$ and washed with d.d. $\mathrm{H}_{2} \mathrm{O}$. To co-stain for $\mathrm{CAA} /$ fibrillar $\mathrm{A} \beta$, sections were subsequently incubated in a $0.25 \%$ aqueous solution of potassium permanganate for $20 \mathrm{~min}$, washed, incubated in an aqueous solution of $2 \%$ potassium disulphite and $1 \%$ oxalic acid for $2 \mathrm{~min}$; washed, incubated in $0.25 \%$ acetic acid for $5 \mathrm{~s}$; washed, incubated in a $50 \%$ ethanol solution of $0.0125 \%$ Thioflavin $\mathrm{S}$; washed and mounted as described above. All chemicals were purchased from Sigma-Aldrich, Switzerland. Prussian Blue was detected using bright field microscopy; ThioS using fluorescence microscopy with excitation and emission wavelengths at 490 and $514 \mathrm{~nm}$, respectively.

\section{Ex vivo astrocyte cultures}

Astrocytes were cultured from early and mid-stage pathology TG and $\operatorname{arcA} \beta$ NTG mice. For the isolation of adult mouse brain astrocytes, mice were deeply anaesthetised using a cocktail of $1.25 \%$ ketamine and $0.25 \%$ xylazine. Working on ice, meninges and cerebellum + brain stem were carefully removed, the remaining brain tissue minced into small pieces and homogenised in culture medium (DMEM/F12 containing L-glutamine $2 \mathrm{mM}$, FCS 10\%, PenStrep 1.0\% (all from Invitrogen, Switzerland)) using a glass homogeniser with Teflon pestle (Wheaton, USA). Brain homogenates were cultured in poly-L-lysine-coated $75 \mathrm{~cm}^{2}$ cell culture flasks (TPP, Switzerland) at $37^{\circ} \mathrm{C}, 5.0 \%$ $\mathrm{CO}_{2}$ and $100 \%$ humidity. After the cells had reached 80-90\% confluence (about 4-6 weeks), the oligodendrocytes layer was detached and removed by shaking of the culture flasks and the medium aspirated. Trypsin/EDTA buffer (Invitrogen, Switzerland) was added to the remaining astrocytes and left for $2 \mathrm{~min}$ at $37^{\circ} \mathrm{C}$. Culture medium was added and the astrocytes in the medium centrifuged at $1,250 \mathrm{rpm}$ for $10 \mathrm{~min}$. Pellets were homogenised in a fresh culture medium and astrocytes were seeded in poly-Llysine-coated 6-well culture plates (TPP, Switzerland), $1.0 \times 10^{6}$ cells in $2 \mathrm{ml}$ culture medium per well or $10 \mathrm{~cm}$ culture Petri dishes $\left(2.0 \times 10^{6}\right.$ cells in $10 \mathrm{ml}$ culture medium per dish). Cells were grown to 80-90\% confluence and split or frozen and stored in liquid nitrogen at $-196^{\circ} \mathrm{C}$.

\section{Microdialysis surgery}

Surgery for microdialysis studies was performed in mid-stage pathology arcA $\beta$ mice which were deeply anaesthetised by an intraperitoneal injection $(100 \mu \mathrm{l} / 10 \mathrm{~g}$ body weight $)$ of a cocktail consisting of fentanyl $50 \mu \mathrm{l} / \mathrm{ml}$, midazolam $5.0 \mathrm{mg} /$ $\mathrm{ml}$ and medetomidin $1 \mathrm{mg} / \mathrm{ml}$ in $0.9 \%$ sterile saline. To prevent drying of the cornea, an eye cream (Viscotears ${ }^{\circledR}$, carbomerum 980, $2.0 \mathrm{mg}$ ) was applied onto the eyes. Body temperature was controlled throughout all the surgical procedures by means of a rectal probe connected to a whole body heating pad set at $37^{\circ} \mathrm{C}$. Mice were placed in a stereotactic frame and the skull was exposed. A small hole was drilled to allow the implantation of a microdialysis guide cannula (CMA/7, Aurora Borealis Control B.V. Schoonebeek, The Netherlands) in the hippocampus [relative to bregma (in $\mathrm{mm})$ : AP: $-3.1 ; \mathrm{L}:+3.0 ; \mathrm{V}:-2.0]$. Two support screws were placed to hold the guide, which was glued to the skull with dental acrylic cement (Pattern Resin, GC Europe, Switzerland). A subcutaneous injection of the analgesic Metacam ( $1 \mu \mathrm{g} / \mathrm{g}$ body weight) was administered directly after surgery followed by an antidote (intraperitoneal injection of $100 \mu \mathrm{l} /$ $10 \mathrm{~g}$ body weight of a mixture consisting of naloxon $0.4 \mathrm{mg} /$ $\mathrm{ml}$, flumazenil $0.1 \mathrm{mg} / \mathrm{ml}$ and atipamezol $5.0 \mathrm{mg} / \mathrm{ml}$ in $0.9 \%$ sterile saline) to antagonise the anaesthetic.

\section{Microdialysis experiments}

Eighteen hours prior to the experiment, the microdialysis probe $(\mathrm{CMA} / 7$, cut-off $6 \mathrm{kDa}$, membrane length $1.0 \mathrm{~mm}$, Aurora Borealis Control B.V., Schoonebeek, the Netherlands) was inserted into the guide cannula. The inlet of the microdialysis probe was connected by fluorinated ethylene propylene tubing (FEP tubing, CMA, Sweden) to a syringe pump (Beehive, Bas Technicol, Congleton, UK). The probe was perfused with artificial extracellular fluid (aCSF, composition in $\mathrm{mM}: \mathrm{NaCl} 145 ; \mathrm{KCl} 2.7 ; \mathrm{CaCl}_{2} 1.2 ; \mathrm{MgCl}_{2} 1.0$ in a $2 \mathrm{mM}$ phosphate buffer, $\mathrm{pH}$ 7.4) at a flow rate of $1 \mu \mathrm{l} / \mathrm{min}$. The outlet was connected to another piece of FEP tubing with sample vial attached. Eighteen hours after insertion and start of perfusion of the probe, the actual experiment was started (between 08:00 and 09:00 a.m.). To assess the baseline glucose differences between TG and NTG arcA $\beta$ mice, 20 samples with 30-min intervals were collected. Each sample vial was put on dry ice directly after the sampling time was over and exchanged for a new, empty one. For glucose uptake measurements, mice were fasted for $12 \mathrm{~h}$ prior to the experiment. After collection of three 30-min interval microdialysis samples (for baseline glucose measurements), mice were given an intraperitoneal injection of $250 \mathrm{mg}$ glucose in PBS/kg body weight during continuous microdialysis sampling. Twelve 5-min interval microdialysis samples were collected, followed by four 30-min samples. Fifteen min before the sampling time of the last 30-min interval sample had ended, aCSF perfusate was changed to aCSF containing potassium chloride $(\mathrm{KCl}) 120 \mathrm{mM}$ using a liquid switch (CMA, Sweden). These 15 min were calculated based on the dead volume of the FEP tubing and microdialysis probe in- and outlet. Two 5-min samples were collected after which an intraperitoneal injection of $250 \mathrm{mg}$ 
glucose in PBS/kg body weight was given during continuous microdialysis sampling. Twelve more 5-min interval samples were taken followed by two 30-min collections. Each sample vial was put on dry ice immediately after its sampling time was over and exchanged for a new, empty one.

Glucose and lactate assays

Glucose was measured using the Amplex ${ }^{\circledR}$ Red Glucose/ Glucose Oxidase Assay Kit from Invitrogen, Switzerland. Microdialysis samples were diluted 1:5 and blood samples $1: 20$, cell culture media were used undiluted; processing of samples and assay was performed according to the manufacturer's directions. Lactate assays were performed with an in-house made lactate assay: cell culture media samples were used undiluted whereas microdialysis samples were diluted 1:10 in reaction buffer $\left(\mathrm{KH}_{2} \mathrm{PO}_{4} 10 \mathrm{mM}, \mathrm{pH}\right.$ 6.6, with flavin adenine dinucleotide $0.01 \mathrm{mM}$ ) and $50 \mu \mathrm{l}$ of these samples and $50 \mu \mathrm{l}$ of lactate calibration standards (L-lactate, Sigma-Aldrich, Switzerland) were mixed with $50 \mu$ lactate assay reaction mix $[5 \mathrm{ml}$ lactate reaction mix contained $30 \mu \mathrm{l}$ Amplex ${ }^{\circledR}$ Red $10 \mathrm{mM}$ (Invitrogen, Switzerland), $80 \mu \mathrm{l}$ horseradish peroxidase $10 \mathrm{U} / \mathrm{ml}$ (Invitrogen, Switzerland), $30 \mu$ lactate oxidase $100 \mathrm{U} / \mathrm{ml}$ (Sigma-Aldrich, Switzerland) in $4.86 \mathrm{ml}$ reaction buffer] followed by a $20 \mathrm{~min}$ incubation at $37^{\circ} \mathrm{C}$. Fluorescence was read using a fluorescence reader (SpectraMax Gemini XS, Bucher Biotec AG, Switzerland). Excitation and emission were set at 540 and $590 \mathrm{~nm}$, respectively.

Primary antibodies

Primary antibodies used for immunohistochemistry and western blotting: glucose transporter 1 (GLUT1, Alpha Diagnostic, GT11-A; GLUT1, Abcam, ab40084), glucose transporter 3 (GLUT3, Alpha Diagnostic, GT31-A), endothelial cells (CD31/PECAM1, BD Pharmingen, 553370), APP/A $\beta$ (6E10, Covance/Signet, SIG-39300), A $\beta$ (in-house produced antibody recognising fibrillar $A \beta$ ), laminin (SigmaAldrich, L9393), $\beta$ actin (Abcam, ab6276), lactate transporter 1/monocarboxylate transporter 1 (MCT1, Alpha Diagnostic, MCT-13A), glial fibrillary acidic protein (GFAP, Advanced Immunochemical Inc., 031223), alpha smooth muscle actin (Sigma-Aldrich, A2547), $\beta$ dystroglycan (Abcam, ab49515).

\section{Results}

Decreased endothelial and astrocytic GLUT1

expression in mid-stage $\operatorname{arc} \mathrm{A} \beta$ mice

Western blot analysis of cortex and brain homogenates from mid-stage TG arcA $\beta$ mice and their NTG littermates revealed that the expression of the endothelial GLUT1 protein (55 $\mathrm{kDa}$ isoform) was reduced in the TG animals (Fig. 1d). This phenomenon was observed starting in TG mice around mid-stage disease pathology, an age group at which diffuse and vascular $A \beta$ plaque pathology becomes wide-spread in our TG arcA $\beta$ mice. The decrease in GLUT1 protein expression was more pronounced in the hippocampus than in the cortex. Moreover, ex vivo astrocytic cultures from these mid-stage TG arcA $\beta$ mice were found to express less GLUT1 protein (45 kDa isoform) as compared to astrocytes from their NTG littermates (Fig. 3a). Immunohistochemical staining of free-floating brain sections revealed that the expression of GLUT1 protein but not that of the endothelial marker CD31 was significantly reduced mainly on blood vessels affected by CAA (Fig. 1a, c). Yet, in brain regions with a dense population of diffuse plaques GLUT1 staining pattern on blood vessels was affected as well, being more intervallic in contrast to the continuous expression of CD31 (Fig. 1b). No differences in expression level of the neuronal GLUT3 protein between TG and NTG brain homogenates were observed (Fig. 1d). The apparent difference in GLUT1 reduction between biochemical analysis (Fig. 1d) and histochemical quantification (Fig. 1c) is due to the fact that biochemical analysis was performed on whole brain extracts (excluding cerebellum) and histochemical quantification took account of GLUT1 reduction on CAA-affected vessels only. As can be seen from Fig. 1b also in areas with high abundance of diffuse $A \beta$ plaques endothelial GLUT1 was decreased, an additional decrease that has to be added to the GLUT1 reduction as found on CAA-laden vessels.

Reduced brain baseline glucose concentrations and impaired blood-to-brain glucose uptake in mid-stage $\operatorname{arc} \mathrm{A} \beta$ mice

To investigate whether reduced GLUT1 protein expression would cause decreased glucose concentration in hippocampal extracellular fluid (ECF), in vivo hippocampal microdialysis was performed. Baseline hippocampal glucose concentrations measured continuously over $10 \mathrm{~h}$ were found to be lower in TG animals as compared to their NTG littermates (Fig. 2a). No such differences were found in plasma glucose levels (Fig. 2b) and a systemic cause for the hippocampal glucose deficiencies as present in the TG animals could hence be ruled out. To investigate if these chronically decreased ECF glucose baseline concentrations in the TG arcA $\beta$ mice were indeed caused by insufficient blood-to-brain glucose uptake due to decreased GLUT1 expression, glucose uptake was assessed (Fig. 2c). After a $12 \mathrm{~h}$ period of fasting and collection of four 30-min interval microdialysis samples (for baseline glucose measurements), mice were given an intraperitoneal injection of $250 \mathrm{mg}$ glucose $/ \mathrm{kg}$ body weight 


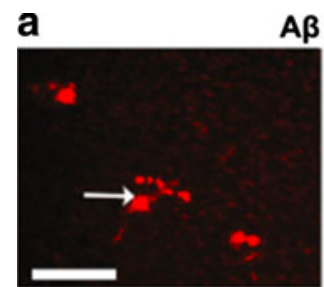

$A \beta$

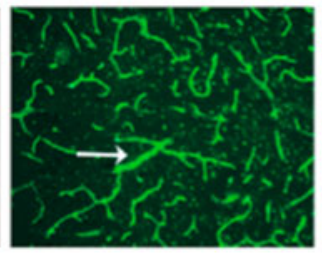

b
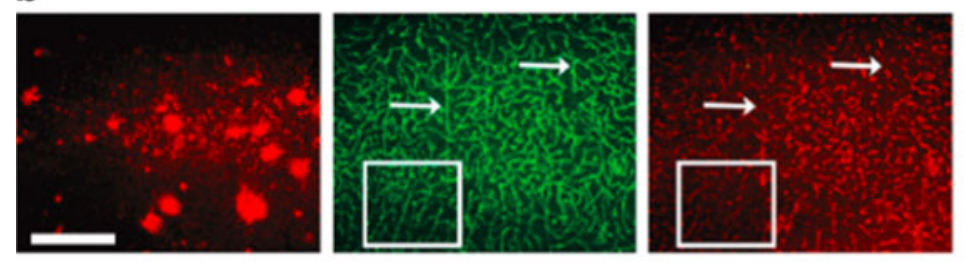

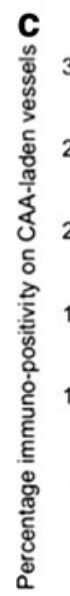

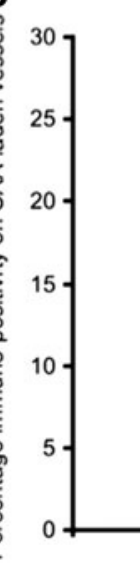

Fig. 1 Endothelial GLUT1 but not neuronal GLUT3 protein expression and basal glucose levels are decreased in the TG arcA $\beta$ mouse brain from mid-stage pathology onwards. a Immunohistochemical staining of a representative cortical brain section showing GLUT1 protein expression on CAA and non-CAA blood vessels in a midstage TG arcA $\beta$ mouse. Reduced GLUT1 immuno-staining (arrow) on a CAA-vessel (stained with antibody 6E10, arrow) can be seen. However, CD31-a marker for endothelial cells - was not affected and eventual impaired staining for GLUT1 due to antigen-masking by CAA (arrow) could be ruled out. b Immunohistochemical staining of a representative cortical brain section of a mid-stage $\operatorname{arcA} \beta$ mouse shows that in areas with dense presence of diffuse $A \beta$ plaques also non-CAA vessels had reduced GLUT1 protein expression, whereas

during continuous microdialysis sampling (Fig. 2c, sample 5, single arrow). Fifteen 5-min interval microdialysis samples were collected (samples 5-19), followed by four 30-min samples (samples 20-23). Whereas in the microdialysate of the NTG animals first a clear fall in glucose was measured in the 5-min interval microdialysate sample collected during and directly after injection of glucose (sample 5, single arrow) and then a steep rise to a new glucose concentration plateau was established, no such change in the glucose concentration profile was seen in the TG arcA $\beta$ mice. Contrary to these findings, retrodialysis of $120 \mathrm{mM}$ potassium chloride $(\mathrm{KCl})$ to stimulate neuronal activity combined with intraperitoneal

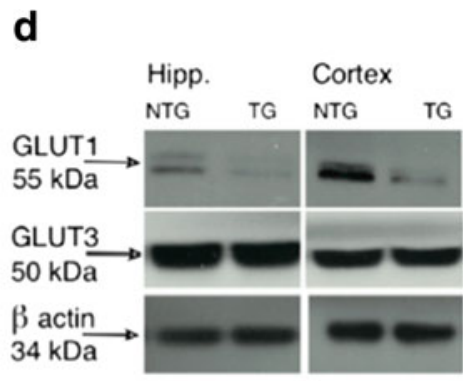

$* p<0.001$

\section{GLUT1}

CD31 staining was preserved on these vessels (arrows). CD31 was found to be continuously expressed on the whole length of the vessels in contrast to GLUT1 which showed interruptions in the staining pattern (outlined section). c Statistical analysis of CD31 and GLUT1 expression on CAA-vessels in mid-stage arcA $\beta$ mice. Immunostaining for GLUT1 was significantly lower on these CAA-vessels as compared to the CD31 staining. Student's $t$ test, $p=0.0004(n=35$ CAA vessels). d Western blots of hippocampus and cortex of midstage TG arcA $\beta$ mice and NTG littermates demonstrating that the endothelial GLUT1 protein expression $(55 \mathrm{kDa})$ was reduced in TG animals as compared to their NTG littermates. No differences were found in the levels of the neuronal GLUT3 protein. Scale bar a $100 \mu \mathrm{m} ; \mathbf{b} 300 \mu \mathrm{m}$

administration of $250 \mathrm{mg}$ glucose $/ \mathrm{kg}$ body weight (Fig. 2c, sample 24, double arrows) led to a sharp fall and then steep rise in glucose concentration in the microdialysate of both NTG and TG mice.

Impaired lactate release upon neuronal stimulation and reduced expression of the astrocytic lactate transporter MCT1 in mid-stage $\operatorname{arcA} \beta$ mice

To analyse the consequences of impaired glucose concentration profiles on neuronal functioning, the release of lactate during neuronal stimulation was assessed. Lactate 

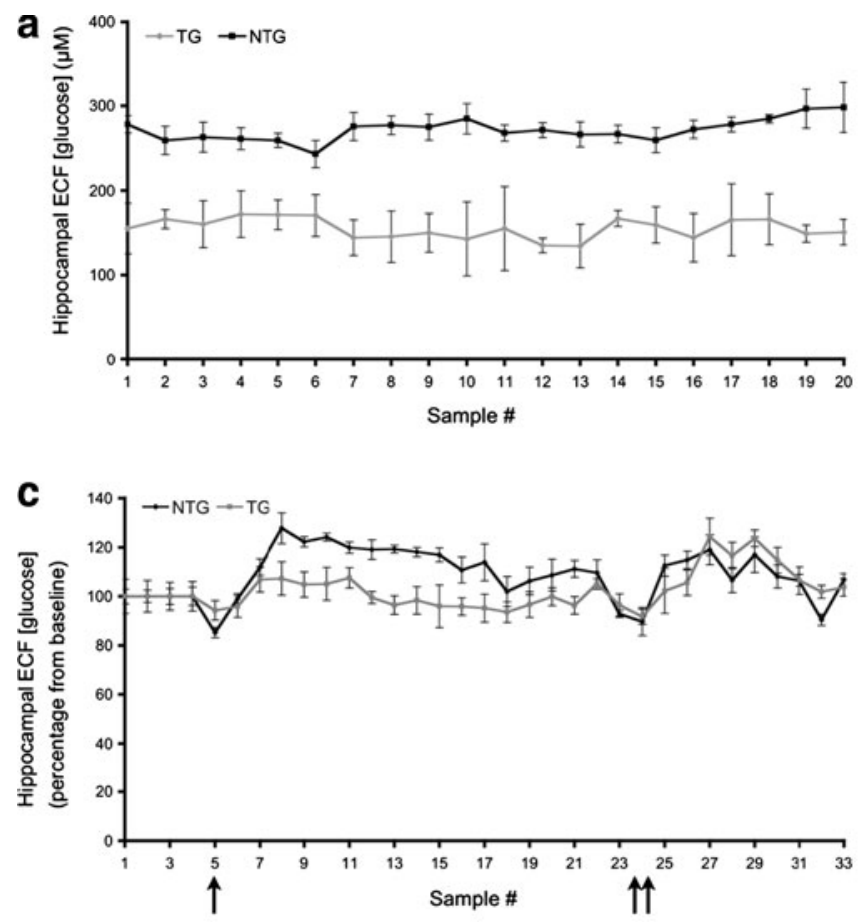

Fig. 2 Blood-to-brain glucose uptake and astrocytic lactate release upon neuronal stimulation are impaired in TG $\operatorname{arcA} \beta$ mouse brain starting at mid-stage pathology. a Lower baseline glucose concentration profile in hippocampal ECF microdialysate of mid-stage TG $\operatorname{arcA} \beta$ mice as compared to their NTG littermates. Microdialysis samples were taken in 30-min intervals over $10 \mathrm{~h}$. On average baseline hippocampal glucose was about $30 \%$ lower in TG animals as compared to their NTG littermates. Note the higher degree of intraindividual deviation in the TG animals, possibly due to the heterogeneity of CAA and/or A $\beta$ plaque load in this group. b No differences were found in plasma glucose levels between TG $\operatorname{arcA} \beta$ mice and their NTG littermates. Blood was withdrawn from the tail vein of the mice after an 8-h period of fasting. Mean plasma glucose concentration for both TG and NTG animals was around $3.5 \mathrm{mmol} / \mathrm{l}$. c Graph illustrating impaired rise in glucose in hippocampal ECF of TG $\operatorname{arcA} \beta$ mice upon systemic administration of glucose alone (sample 5, single arrow) and in combination with neuronal stimulation using potassium chloride $(\mathrm{KCl})$ (sample 24 , double arrows). Intraperitoneal injection of $250 \mathrm{mM}$ D-glucose in TG arcA $\beta$ mice and

is derived from glucose and released by astrocytes upon uptake of neuronal-secreted glutamate in the synaptic cleft during neuronal stimulation [32, 37, 38]. Lactate was measured in the same microdialysate samples as collected for glucose uptake analyses (Fig. 2d). As can be seen from Fig. 2d, baseline lactate levels were not different between TG animals and their NTG littermates and not affected by intraperitoneal administration of glucose (sample 5, single arrow). However, retrodialysis of $120 \mathrm{mM} \mathrm{KCl}$ led to a fast and steep increase in lactate levels in the microdialysate of NTG animals, a response which was less pronounced (sample 24, double arrows) and more protracted in the TG mice (samples 24-27). b
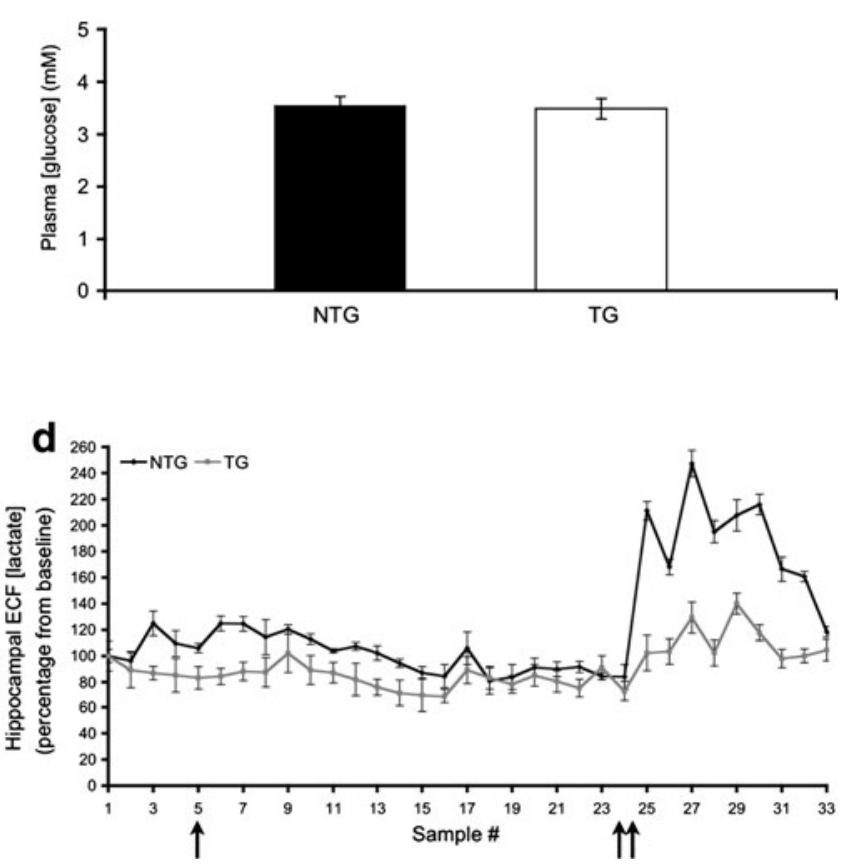

their NTG littermates (sample 5, single arrow) after $12 \mathrm{~h}$ of fasting led to a sharp increase in hippocampal ECF glucose in NTG animals, whereas the TG animals did not demonstrate such rise in glucose levels. However, intraperitoneal injection of $250 \mathrm{mM}$ D-glucose in combination with neuronal stimulation by retrodialysis of $120 \mathrm{mM}$ $\mathrm{KCl}$ (sample 24, double arrows) into the hippocampal ECF both TG and NTG animals showed an increase in glucose. $\mathbf{d}$ Impaired increase in lactate concentrations in TG animals upon neuronal stimulation. No difference in basal lactate levels was found between TG animals and their NTG littermates (samples 1-23). Lactate was measured in the same microdialysate samples as collected for glucose uptake analyses (Fig. 2a). Note that intraperitoneal administration of glucose did not have an effect on lactate concentrations (sample 5, single arrow). Retrodialysis of $120 \mathrm{mM} \mathrm{KCl}$ (sample 24, double arrows) led to a fast and steep increase in lactate levels in the microdialysate of NTG animals, a response which was not found in the TG mice. The TG animals showed slower and smaller rise in lactate and a delay in the time to reach baseline concentrations

This finding prompted us to further study the possibility of a deficiency in lactate release by $\operatorname{arcA} \beta$ astrocytes. To this aim, the expression of the astrocytic lactate transporter monocarboxylate transporter 1 (MCT1)-which transports lactate from the astrocyte cytoplasm into the ECF where it can be taken up by neurons-was assessed as well as the concentration of lactate released in culture medium of ex vivo-cultured astrocytes derived from the same cohort of mid-stage $\operatorname{arcA} \beta$ mice. A strongly reduced expression of the lactate transporter was found in the astrocyte lysates as demonstrated by WB (Fig. 3a) as was a significantly decreased lactate release ex vivo (Fig. 3b). 

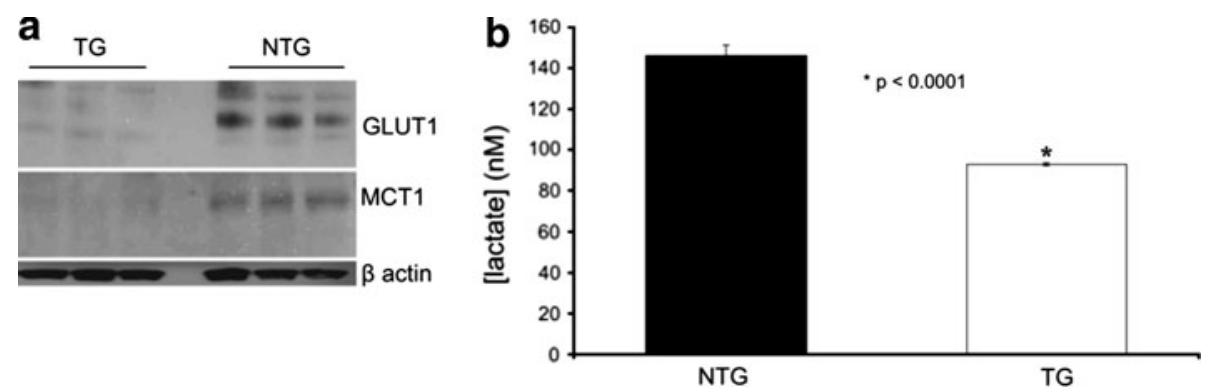

Fig. 3 Expression of the astrocytic glucose and lactate transporter involved in cerebral metabolism and neuronal functioning is reduced in astrocytes cultured from mid-stage $\mathrm{TG} \operatorname{arcA} \beta$ mouse brain with concomitant decreased lactate release. a GLUT1 and MCT1 (astrocytic lactate transporter) were down-regulated in whole cell lysate preparations of astrocyte cultures originating from mid-stage TG

Early-stage astrogliosis precedes wide-spread $\mathrm{A} \beta$ plaque burden and is paralleled by increased vascular basement laminin staining and increased soluble laminin secretion by $\mathrm{TG} \operatorname{arc} \mathrm{A} \beta$ astrocytes ex vivo

Astrogliosis was found in all three disease stages in TG $\operatorname{arc} \mathrm{A} \beta$ mice, increasing with age, especially surrounding diffuse $A \beta$ plaques in the neuropil and vessels bearing $\mathrm{CAA}$ or vascular $\mathrm{A} \beta$ deposits. The presence of astrogliosis in the early-stage mice was found around arteries descending from leptomeningeal vessels and was remarkable since only little extracellular $A \beta$ plaque burden was present in this age group (Fig. 4a). The extensive astrogliosis around these blood vessels was paralleled by an increased immunoreactivity against laminin (Fig. 4a), a major component of the VBM. Moreover, astrocytes themselves were clearly immunopositive for laminin too; especially astrocytic dendrites presented a strong laminin staining (Fig. 4b, arrow). Laminin was concentrated around and within the astrocytes and following the astrocytic staining structure rather than that for $A \beta$ (Fig. $4 b$ ). Interestingly, a more diffuse laminin staining was observed around astrocytes as well (Fig. 4b, asterisk). It is known that astrocytes can secrete laminin [8] and we, therefore, measured soluble laminin in media of TG and NTG ex vivo-cultured astrocytes derived from early and mid-stage $\operatorname{arc} \mathrm{A} \beta$ mice. The TG astrocytes in both the age groups were found to secrete more laminin than their NTG counterparts (Fig. 4c, early-stage and d, mid-stage).

A $\beta$ induces astrocyte endfeet retraction leading to neurovascular uncoupling, starting at early-stage pathology

To further investigate the astrocytic abnormalities found in the TG $\operatorname{arcA} \beta$ mice, we studied the structural appearance of astrocyte endfeet at early and late pathological stages of the
$\operatorname{arcA} \beta$ mice. Staining for $\beta$ actin served as loading control for all samples. b Astrocytic lactate release in media of the same astrocyte cultures originating from mid-stage TG and NTG arcA $\beta$ mice. A decreased lactate concentration was found in culture media of TG astrocytes as compared to astrocytes from NTG littermate brains

disease (Fig. 5). As was observed in other transgenic $\mathrm{AD}$ mouse models [61] we found signs of neurovascular uncoupling suggested by swelling and retraction of astrocyte endfeet of astrocytes surrounding (vascular) $A \beta$ deposits in both early and late-stage animals (Fig. 5a, b). Although the cerebrovasculature in late-stage arc $A \beta$ mice is severely affected by CAA, we found that on non-CAA-laden vessels in these aged mice contacts between astrocyte endfeet and the vasculature was maintained (Fig. 5b, arrows). An A $\beta$-induced endfeet detachment and swelling was further suggested by the observation of astrocyte endfeet swelling and endfeet loss of astrocytes surrounding diffuse $A \beta$ plaques (Fig. 5b, asterisk) similar to CAA-induced endfeet abnormalities (Fig. 5a, arrows). Furthermore, astrocytes surrounding the small number of $A \beta$ deposits which were present in the early-stage mice, all showed endfeet abnormalities.

Loss of astrocytic $\beta$ dystroglycan expression in late-stage TG $\operatorname{arc} \mathrm{A} \beta$ mice is consistent with decreased interactions between astrocyte endfeet and vasculature and is paralleled by cerebral extravasation of blood-derived IgG

Astrocyte endfeet attach to cerebral vessels via interactions between endfeet $\beta$ dystroglycan and vascular laminin [2,53]. To understand if the observed astrocyte endfeet retractions as shown in Fig. 5 could be associated with impaired $\beta$ dystroglycan-laminin interactions, the expression of astrocytic $\beta$ dystroglycan was explored. We found that the astrocytic expression of $\beta$ dystroglycan was significantly decreased in TG arcA $\beta$ mice (Fig. 6a, c, e, g). Loss of $\beta$ dystroglycan was paralleled by the cerebral presence of endogenous mouse $\mathrm{IgG}$ around diffuse $\mathrm{A} \beta$ plaques (Fig. 6a, c, and e, arrows) and was most pronounced in the cortical regions and hippocampus (Fig. 6a, e and s). The presence of mouse IgG was detected by the same secondary anti-mouse antibody (fluorescein isothiocyanate/FITC-tagged donkey anti-mouse IgG, Jackson 

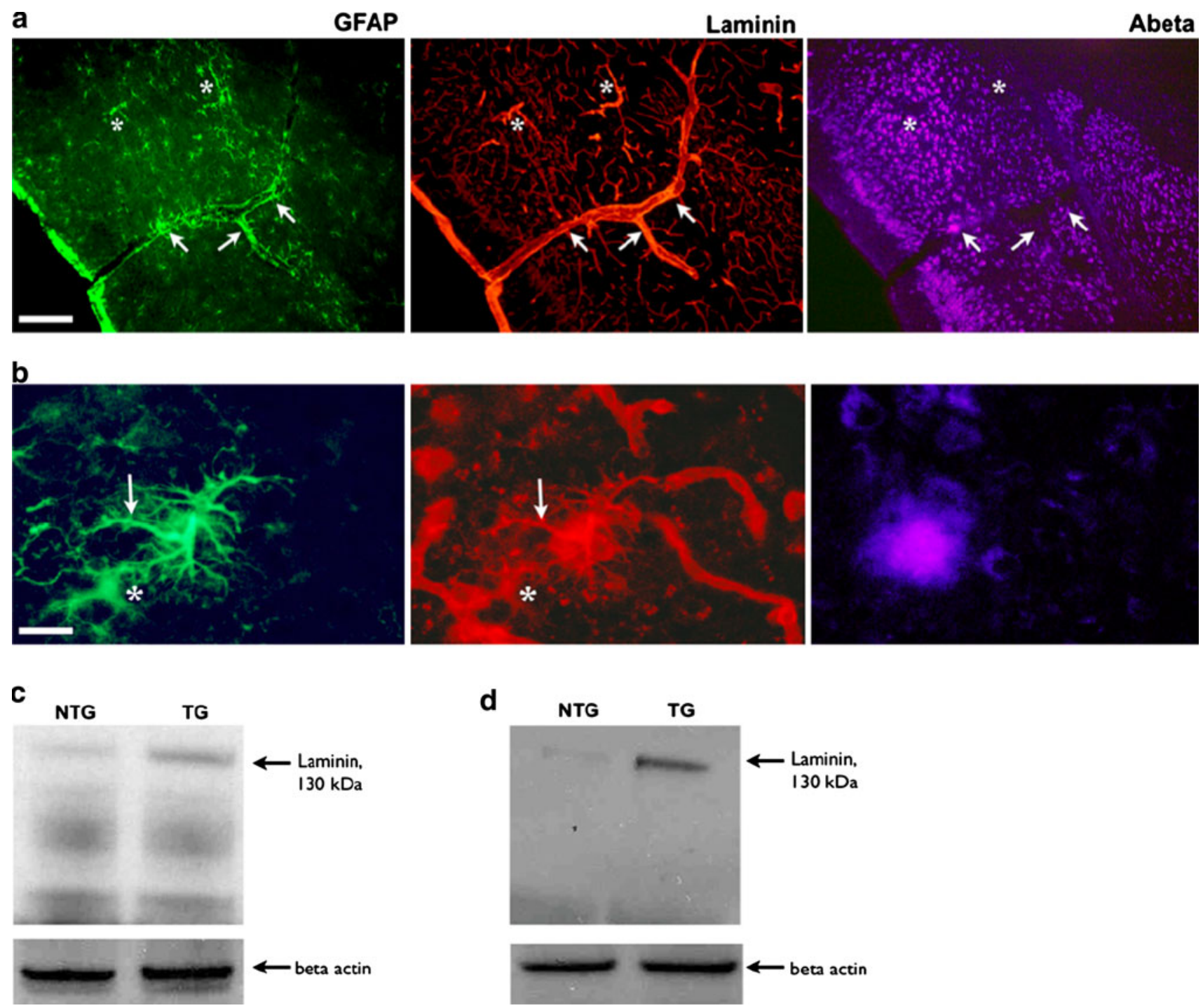

Fig. 4 Intensive astrogliosis with concomitant laminin over-expression is already present in the early-stage TG $\operatorname{arcA} \beta$ mouse brain. a Representative cortical brain section of an early-stage TG $\operatorname{arcA} \beta$ mouse triple-stained for GFAP, laminin and A $\beta / A P P$. Only few diffuse $A \beta$ plaques and little vascular $A \beta$ deposits were seen at this age. However, the presence of astrogliosis (GFAP staining) around some incoming leptomeningeal vessels and arterioles (a, arrows) and small vessels (a, asterisks) in the cortex was already detected at this age with a concomitant increased immunopositivity for laminin. b A $\times 20$ of a representative cortical brain section of an early-stage TG

ImmunoResearch Laboratories, USA) used to visualise the primary anti- $\beta$ dystroglycan antibody which was raised in mouse, explaining the presence of both $\beta$ dystroglycan and endogenous mouse IgG on the same brain sections. Adjacent brain sections immuno-stained with FITC-conjugated donkey anti-mouse IgG secondary antibody only showed the same IgG staining pattern (data not shown). Interestingly, an area of the brain where no extravasated mouse IgG could be observed (the hypothalamic region, Fig. 6c) did show a significantly less pronounced loss of $\beta$ dystroglycan expression
$\operatorname{arcA} \beta$ mouse triple-stained for GFAP, laminin and A $\beta / A P P$. Astrocyte (GFAP) and laminin staining showed expression and/or secretion of laminin in the astrocytic dendrites (arrows) and surrounding the astrocytes (asterisk). Western blots showing a higher amount of laminin in the media of ex vivo astrocyte cultures from early-stage (c) and mid-stage (d) $\mathrm{TG} \operatorname{arcA} \beta$ mice as compared to that of astrocytes from their NTG littermates. Scale bar a $300 \mu \mathrm{m} ; \mathbf{b} 30 \mu \mathrm{m}$. Hue settings of fluorescence for $A \beta$ were altered for more contrast effect explaining the purple colour

(Fig. 6c and g). This area was also spared from diffuse $A \beta$ plaques and $\mathrm{A} \beta$ was rather present as $\mathrm{CAA}$.

$\beta$-amyloid-related pathology of cerebral arteries and arterioles in late-stage $\operatorname{arc} \mathrm{A} \beta$ mice

Vascular corrosion casts and SEM were used to study the vascular morphology in brains of TG and $\operatorname{arcA} \beta$ NTG mice. Severe alterations were seen especially in the morphology of arteries and arterioles of late-stage TG animals as compared 

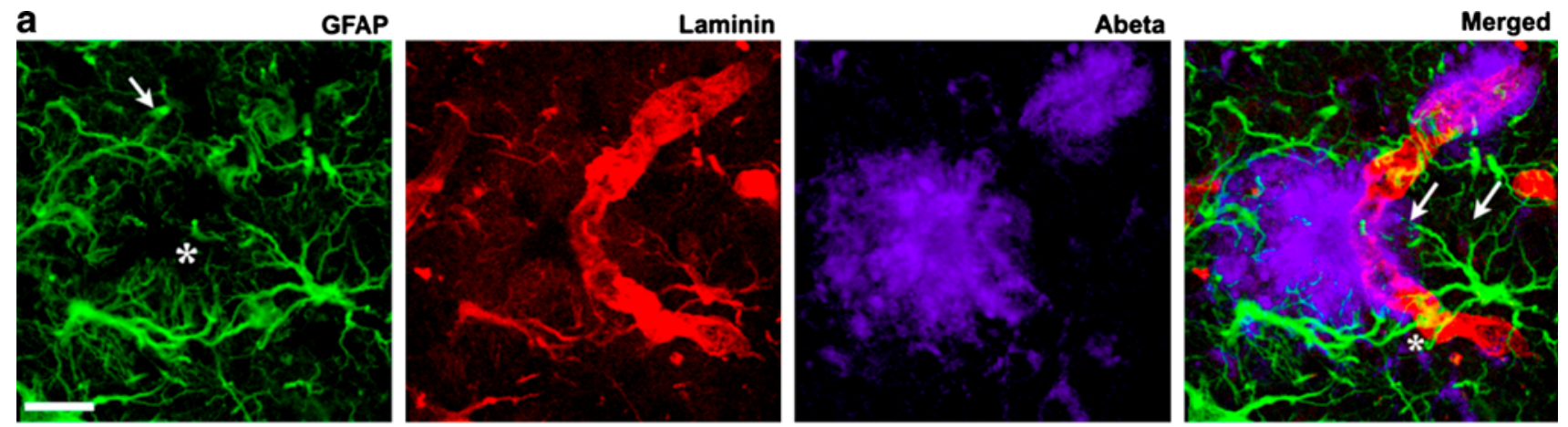

b
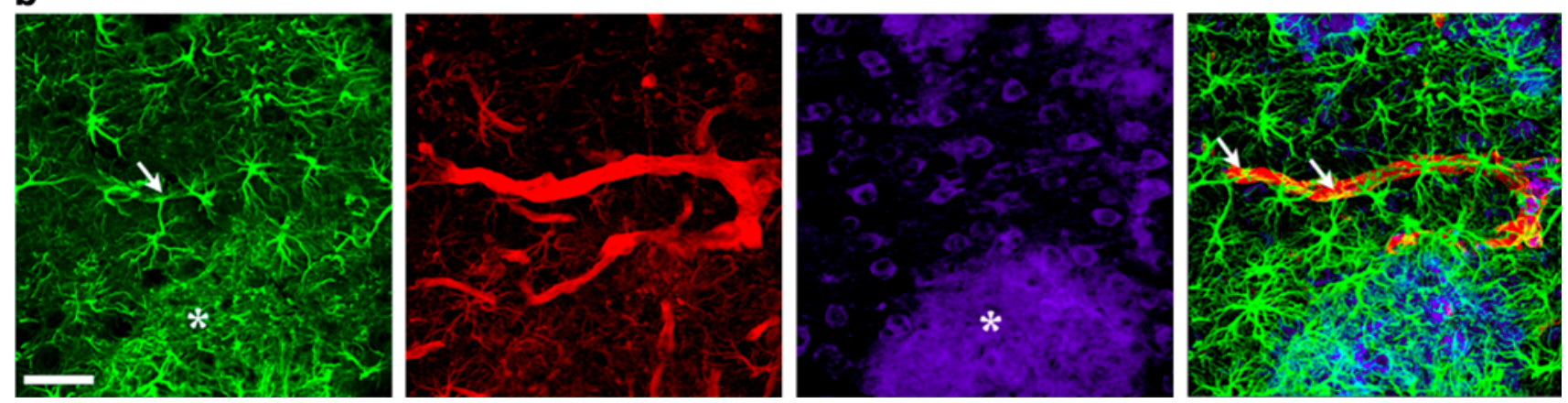

Fig. 5 Diffuse and vascular $A \beta$ deposits induce astrocyte endfeet retraction and swelling in $\mathrm{TG} \operatorname{arcA} \beta$ mice, starting at early-stage pathology. a Representative confocal microscopy images of cortical brain sections of an early-stage TG arc $\mathrm{A} \beta$ mouse triple-stained for GFAP, laminin and A $\beta / A P P$. At this age, TG arc $A \beta$ mice have only few diffuse $A \beta$ plaques and very little CAA but the structural appearance of these $A \beta$ deposits is similar to that in mid-stage and late-stage animals, albeit less dense and restricted in size. Astrocytes (GFAP) surrounding these plaques show swollen endfeet (a, arrows

and asterisk) and loss of endfeet contact at CAA-affected vessels (laminin was used as vessel marker). b Arrows in sections show close endfeet-vessel interactions at a non-CAA-affected vessel in a latestage TG $\operatorname{arcA} \beta$ mouse brain. The same endfeet retractions and swellings as can be seen in a were observed for astrocytes within and surrounding diffuse $\mathrm{A} \beta$ plaques (b, asterisk). Scale bar a $30 \mu \mathrm{m}$; b $150 \mu \mathrm{m}$. Hue settings of fluorescence for $A \beta$ were altered for more contrast effect explaining the blue colour

to their NTG littermates (Fig. 7). The clear and typicallyshaped endothelial imprints as seen in the NTG littermates (Fig. 7a, arrow) were malformed and often abolished in the TG mice (Fig. 7b, arrow). Furthermore, the vessel walls of these arteries and arterioles had a tree bark-like appearance (Fig. 7b, arrow). Severe vessel constrictions, appearing as stenoses, were found on numerous arteries and arterioles (Fig. 7b, asterisks and inset). Protrusions of the perfusion resin were found both on arterioles and capillaries of TG animals, indicating leakage of the vessel walls (Fig. 7c). In addition to these changes in vessel morphology, gaps in the vascular bed were uniquely present in the TG animals (Fig. 7d). Cerebrovascular morphology of early and midstage TG animals was not altered as compared to their NTG littermates (data not shown).

Cerebral hypoperfusion and small cerebral vessel leakages without significant haemorrhaging in late-stage $\operatorname{arcA} \beta$ mice

Mouse brains perfused with casting resin and processed for histological analyses, showed that the presence of vessel

leakages was paralleled by CAA in the TG animals (Fig. 8b, asterisks). These leakages appeared as ballshaped structures protruding out of the vessel wall, similar to the structures observed in the SEM pictures (Fig. 7d). Resin protrusions were not found on vessels of NTG littermates (Fig. 8a). The number of vessels perfused with fluorescent casting resin was lower in the TG animals (Fig. 8b, frame and Fig. 8c) as compared to their NTG littermates (Fig. 8a, frame and Fig. 8c). This was not accompanied by a reduction in vascular density (Fig. 8b GLUT1, frame and Fig. 8d) indicating that the decrease in vascular casting resin penetration was most likely due to the pathological cerebral hypoperfusion in the TG animals. Decreased cerebral perfusion could also explain the gaps in the vascular bed in the TG mice as observed with SEM (Fig. 7d). To assess if casting resin protrusions could be a sign of BBB compromise, TG and arcA $\beta$ NTG mice were intraperitoneally injected with Trypan Blue. Unlike the results seen with the vascular casting resin (Fig. 8) such Trypan Blue-albumin (TBA) extravasations were mainly found around small vessels (Fig. 9a, asterisks). Bigger arterioles and arteries showed a mere accumulation of TBA 

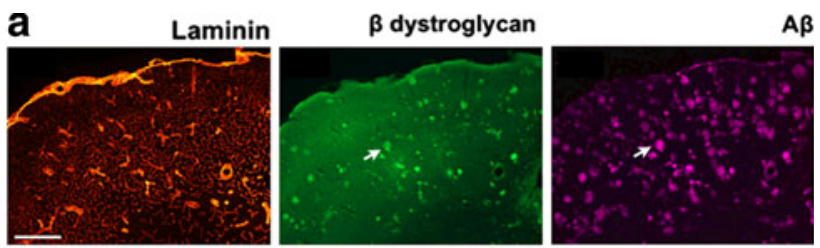

b
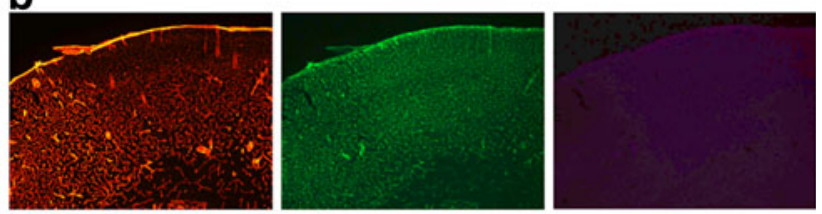

c
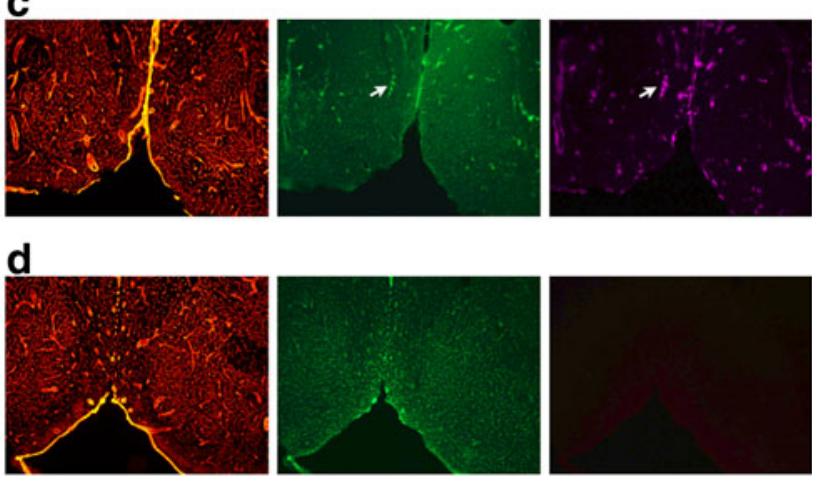

e
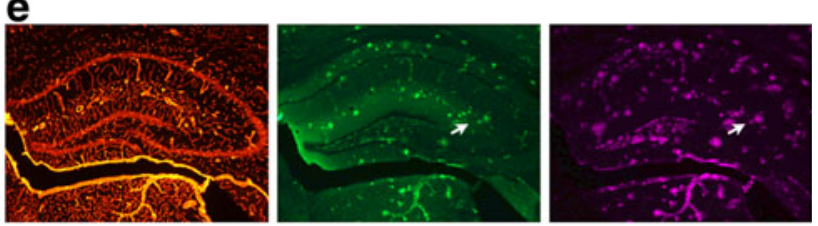

f
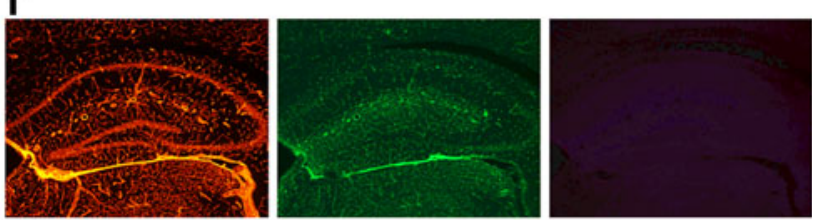

g

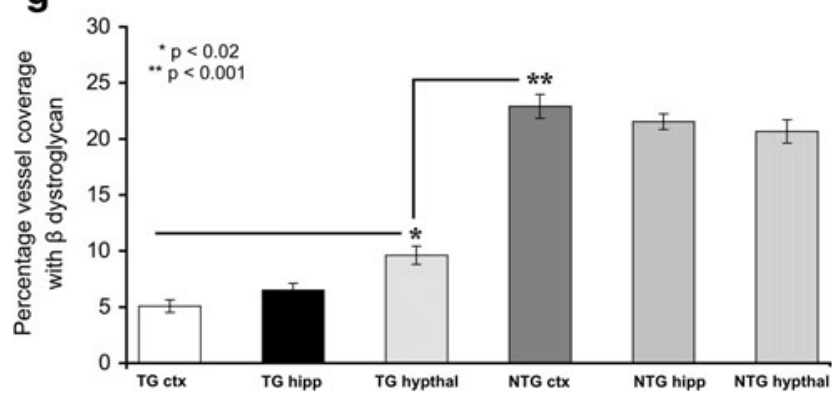

within the vessel wall (Fig. 9a plus sign and arrow, respectively). Similar to the vascular resin histology (Fig. 8) these small vessel TBA extravasations and arterial/ big arteriolar TBA accumulations were only present on CAA-affected vessels (Fig. 9a). Vessels were visualised using a CD31 antibody to stain endothelial cells.
Fig. 6 Astrocytic $\beta$ dystroglycan expression is significantly decreased in late-stage TG $\operatorname{arcA} \beta$ mouse brain and paralleled by IgG extravasation. Representative images of late-stage TG (a, c, e) and $\operatorname{arcA} \beta$ NTG littermate (b, d, f) mice showing decreased expression of the astrocyte endfeet protein $\beta$ dystroglycan in TG $\operatorname{arcA} \beta$ mouse brain as compared to their NTG littermates. Loss of $\beta$ dystroglycan immunoreactivity was most pronounced in the cortex (a) and hippocampus (e) of TG animals. This reduced expression was paralleled by the presence of cerebral extravasation of endogenous $\mathrm{IgG}$ around diffuse $\mathrm{A} \beta$ plaques (a, e, arrows). Areas of the brain (hypothalamic region) where no mouse IgG could be observed did show less pronounced loss of $\beta$ dystroglycan expression (c). These areas were also not affected by diffuse $A \beta$ plaques but rather by CAA. Scale bar a $300 \mu \mathrm{m}$. Presence of mouse IgG was detected by the same secondary anti-mouse antibody (FITC-tagged donkey anti-mouse $\mathrm{IgG})$ used to visualise primary anti- $\beta$ dystroglycan antibody which was raised in mouse, explaining the presence of both $\beta$ dystroglycan and endogenous mouse IgG on the same brain sections. g Significant loss of $\beta$ dystroglycan expression on blood vessels in cortex (ctx), hippocampus (hipp) and hypothalamic region (hypthal) of late-stage TG $\operatorname{arcA} \beta$ mice compared to NTG littermates. The hypothalamic region of TG arcA $\beta$ mice showed significantly more $\beta$ dystroglycan expression as compared to cortex and hippocampus $(p<0.02)$ but was still significantly less than in NTG littermates $(p<0.001)$. $\beta$ dystroglycan immunoreactivity was calculated by measuring staining intensity using ImageJ software. Student's $t$ test, $n=$ respective brain areas of 12 mice (6 TG and $6 \mathrm{NTG}$ ), three sections/brain area/mouse. Hue settings of fluorescence for $A \beta$ were altered for more contrast effect explaining the purple colour

Unlike TBA extravasations, cerebrovascular haemorrhages as detected by Prussian Blue staining were rarely seen but likewise associated with CAA (Fig. 9b, asterisk and $9 \mathrm{c}$ ) with brain areas presenting abundant CAA, e.g. (pre-) frontal cortex, mainly affected. However, the extent of haemorrhagic lesions did not correlate with the severity degree of CAA. Furthermore, casting resin protrusions were not chronically paralleled by haemorrhages (Fig. 9d, arrows).

CAA-dependent abnormalities of vascular basement membranes and degeneration of smooth muscle cells in late-stage $\operatorname{arcA} \beta$ mice

Brains from littermates of the mice used in the SEM vascular corrosion casts (Fig. 7) and which were not perfused with casting resin were processed for immunohistochemistry to analyse the morphological alterations found by SEM. Laminin staining (Fig. 10a) was used as $\mathrm{VBM} /$ vessel marker and its expression found to be significantly increased on CAA-laden vessels in mid- and late-stage TG $\operatorname{arcA} \beta$ mice (Fig. 10c, d), a phenomenon underlying VBM thickening and well known to occur in $\mathrm{AD}$ [16]. Bulges of laminin (Fig. 10a, asterisks) resembling the stenoses observed in the SEM analyses (Fig. 7b, asterisks) and vessel constrictions (Fig. 7c, arrow and Fig. 10a, plus signs) were widely found in the TG animals. Moreover, these vascular malformations 

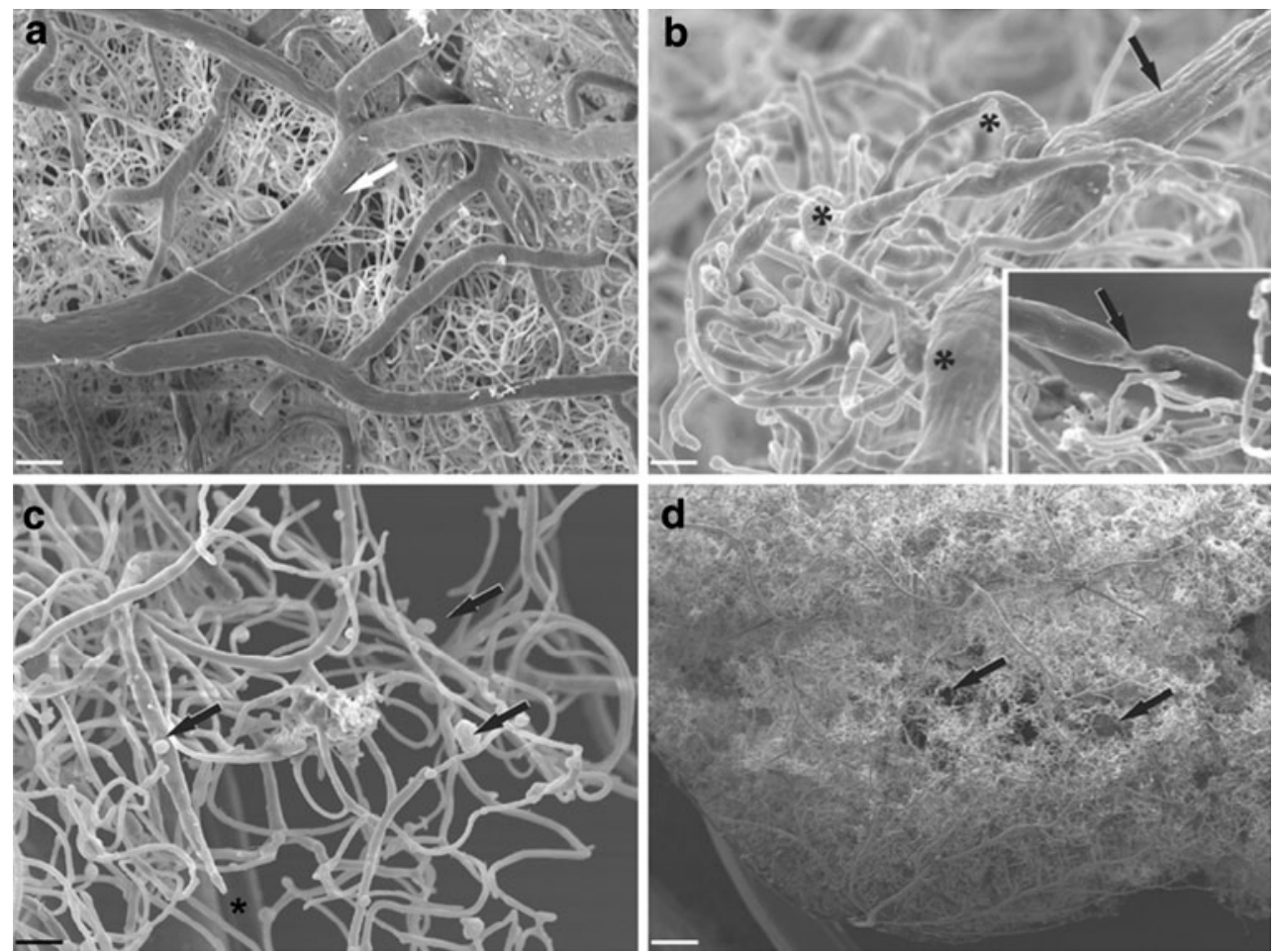

Fig. 7 Morphological alterations of the cerebrovasculature in latestage TG arcA $\beta$ mice. Scanning electron microscopy (SEM) of latestage $\operatorname{arcA} \beta$ NTG littermates showed clear and regular endothelial cell imprints on arterial vessel walls (a, arrow) and a smooth appearance of the vessel wall. In contrast, late-stage TG $\operatorname{arc} \mathrm{A} \beta$ mice presented a tree bark-like vessel wall and degenerated, often absent endothelial cell imprints (b, arrow). Furthermore, extensive stenoses and bulging of the vessel wall were observed both on arteries and arterioles (b, asterisks and inset). Ball-shaped leakages of the perfusion resin were found on arteries, arterioles and capillaries of the TG arcA $\beta$ mice (c, arrows). Loose vessel ends were observed as well (c, asterisk). Whereas the NTG littermates showed a dense and constant vascular bed, the density of the vascular bed in the TG animals was reduced showing numerous gaps, especially in the area of the temporal lobe (d, arrows). Scale bar a $100 \mu \mathrm{m}$; b and c $50 \mu \mathrm{m}$; d $1 \mathrm{~mm}$

\section{Discussion}

(Fig. 10a). Those parts of the same vessels without CAA appeared to be normal and showed no increase in laminin immunoreactivity (Fig. 10a, arrows), indicating a relationship between $\mathrm{CAA}$ and the morphological alterations seen in the SEM analyses (Fig. 7). Severe CAA as uniquely observed in late-stage $\mathrm{TG} \operatorname{arcA} \beta$ mice (Fig. 10b) caused not only such strong laminin up-regulation in the VBM but lead to rupture of the vessel wall as well (Fig. 10b, arrow). In addition, dust-like laminin particles surrounding the ruptured vessels were abundantly observed (Fig. 10b, asterisk). NTG littermates presented typical laminin immunoreactivity of the VBM (Fig. 10b).

Congophilic amyloid angiopathy strongly and significantly affected the expression of vascular SMCs in latestage TG animals with SMC loss paralleled by interruptions in SMC strata (Fig. 11a, arrows and Fig. 11c). In contrast, non-CAA-affected vessels presented intact, uninterrupted vascular SMC layers similar to vessels of their NTG littermates (Fig. 11b).
Vascular pathology is a critical and more and more recognised component of $\mathrm{AD}$, impairing blood-to-brain influx of nutrients essential for cerebral functioning and brain-to-blood efflux of cerebral waste products leading to cognitive deterioration $[10,11,64,65]$. By characterising the transgenic arc $\mathrm{A} \beta$ mouse model of $\mathrm{AD}$ - which presents a strong vascular pathology - at early, mid and late disease stages we investigated what processes could possibly instigate the vascular and metabolic impairments early on in the disease and which mechanisms aggravate the vascular pathology at later stages in this AD mouse model. Decreased endothelial GLUT1 expression has been found in transgenic mouse models of $\mathrm{AD}$ and in human $\mathrm{AD}$ patients [15, 22, 26, 47]. We observed lowered GLUT1 protein expression in TG animals starting at mid-stage disease pathology when CAA formation is apparent in these mice and diffuse $A \beta$ plaques are becoming widespread. As GLUT1 is the sole glucose transporter expressed by brain endothelial cells and peripheral supply is the 

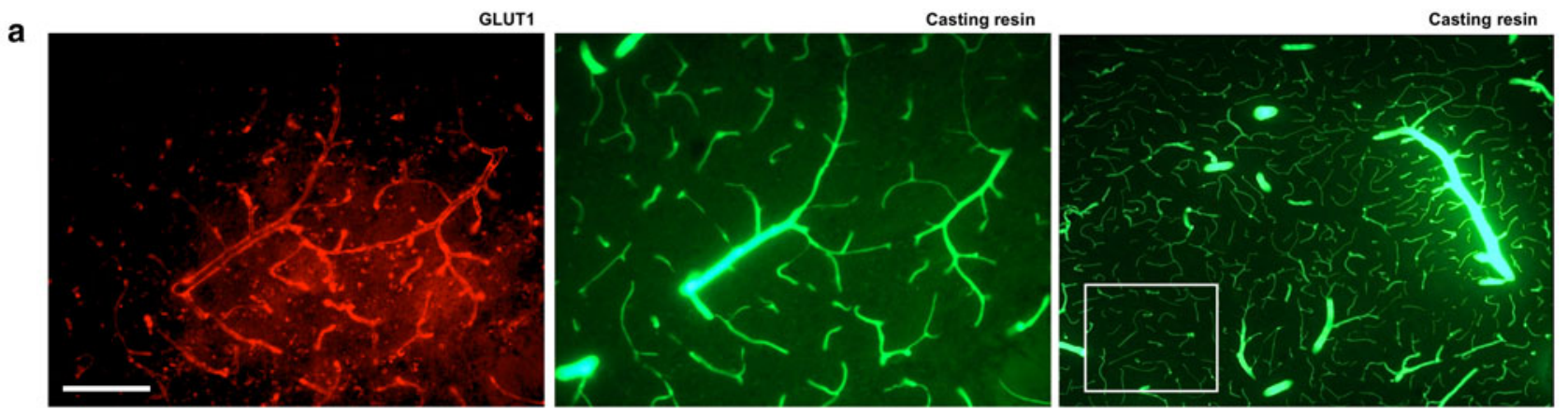

b
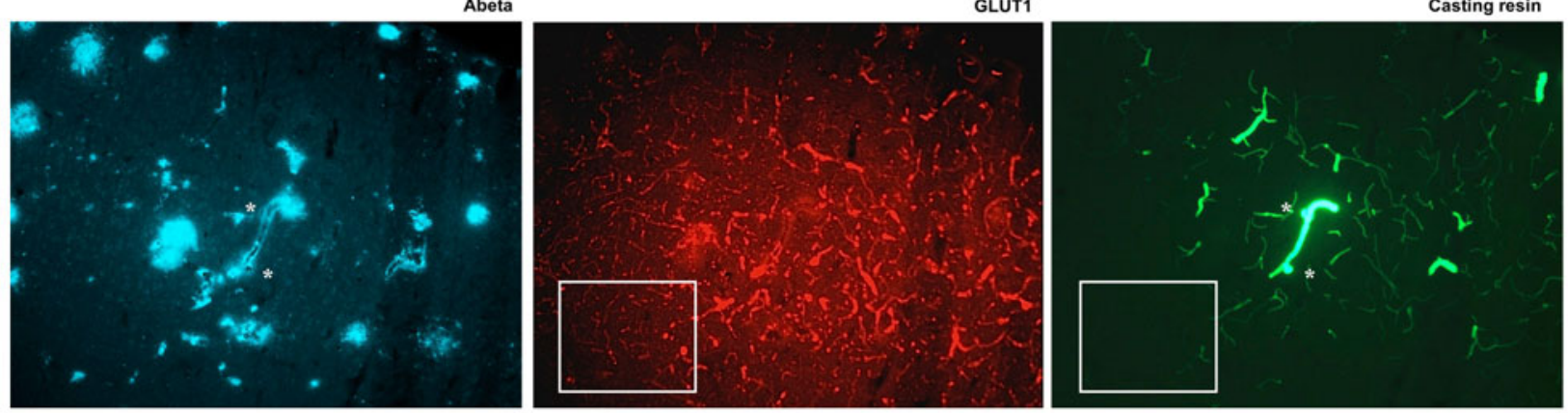

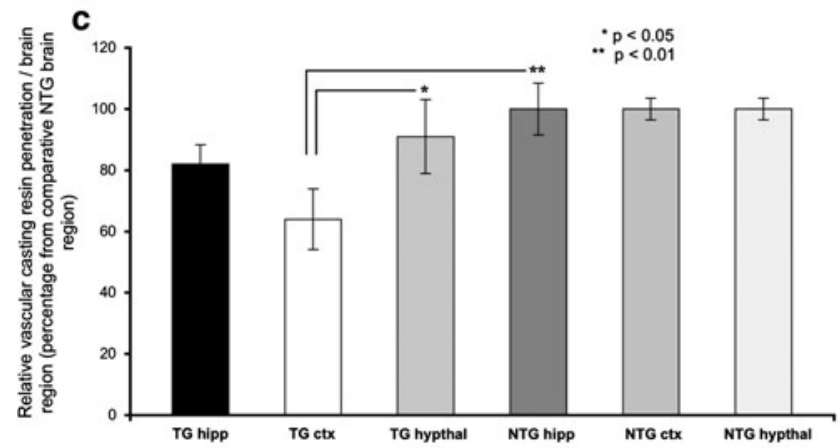

Fig. 8 Leakages of the cerebrovasculature and cerebral hypoperfusion in late-stage TG arcA $\beta$ mice. Brains of littermates of the TG and $\operatorname{arcA} \beta$ NTG mice used for SEM (Fig. 7) were processed for histological purposes after perfusion with vascular casting resin. Perfusion of the cerebrovasculature with the vascular casting resin showed adequate penetration of arteries and smaller vessels (a, frame). TG littermates showed casting resin leakages similar to those observed with SEM (Fig. 7d) (b, asterisks). Perfusion of the

principal source of glucose for the brain [46], it can be appreciated that a decrease in GLUT1 expression will have significant outcomes on cerebral glucose uptake. Indeed, cerebral imaging data from human subjects show a clear correlation between GLUT1 expression and blood-to-brain glucose uptake [12]. Our findings of decreased brain glucose influx and concentration as measured by in vivo microdialysis in TG arcA $\beta$ mice, are in line with these data. The majority of glucose entering the brain via endothelial GLUT1 is subsequently taken up by astrocytes via astrocytic GLUT1 [46]. Astrocyte pathology with altered expression of astrocyte-specific proteins essential for cerebral functioning and metabolism is recognised as a

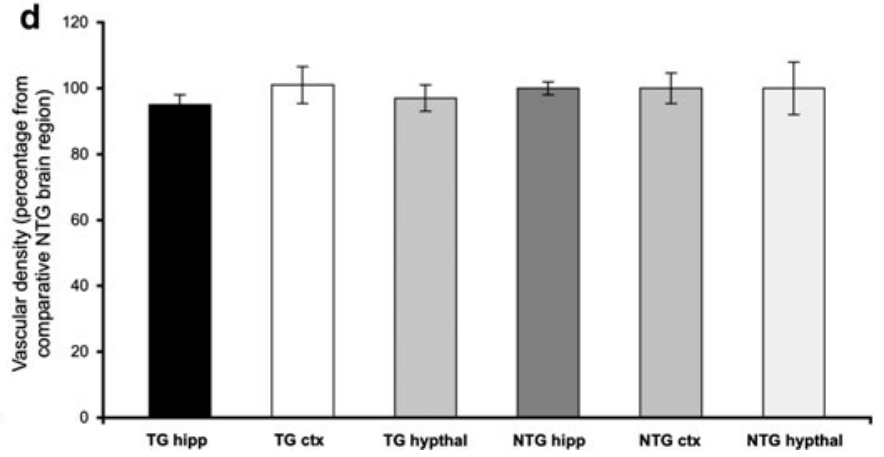

cerebrovasculature with casting resin was, in contrast to the NTG littermates (a, frame), significantly impaired in the cortex showing areas lacking fluorescent casting resin and hence resin-negative vessels (b, frame and $\mathbf{c}$ ). An eventual hypoperfusion due to reduced vascular density was excluded by the finding of GLUT1-positive endothelium in the non-perfused brain areas (b, frame and $\mathbf{d})$. Scale bar a $150 \mu \mathrm{m}$. Hue settings of fluorescence for $\mathrm{A} \beta$ were altered for more contrast effect explaining the purple colour

significant factor in $\mathrm{AD}$ and subject to intensive research $[3,48]$. To understand if a decreased astrocytic GLUT1 expression could also be an underlying factor in the reduced glucose uptake in our microdialysis studies, we cultured astrocytes from the same cohort of $\operatorname{arcA} \beta$ mice ex vivo. We found that its expression was severely affected, starting at mid-stage disease pathology. Astrocytic glucose uptake is a vital step in the cerebral energy apparatus because astrocytes convert glucose into lactate which is used by neurons during neuronal stimulation $[14,29,38$, 43, 44]. Abnormalities in this essential astrocytic contribution to neurometabolic coupling have detectable outcomes on cerebral performance and are known to occur 

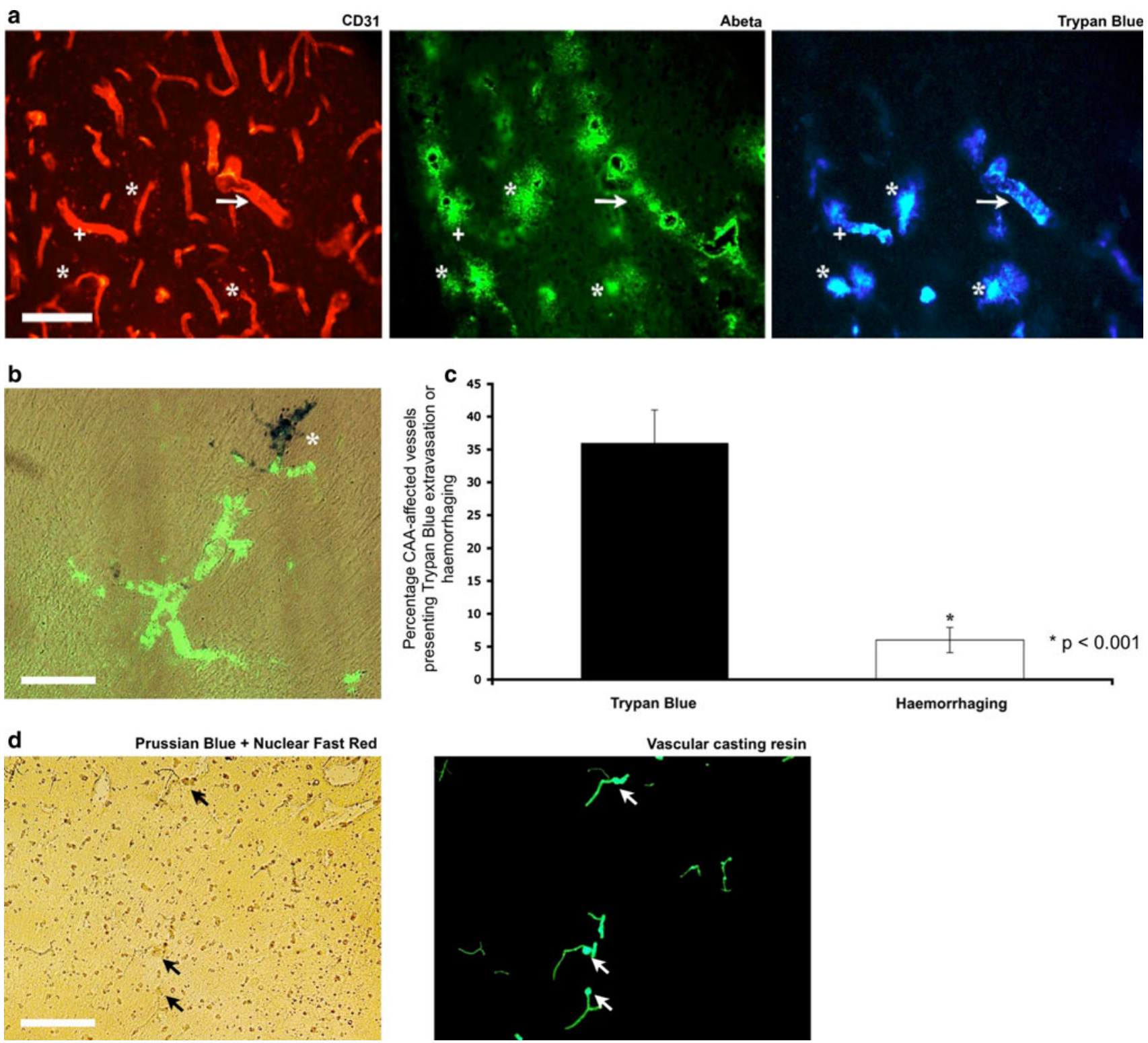

Fig. 9 In vivo leakages of the cerebrovasculature in late-stage TG $\operatorname{arc} \mathrm{A} \beta$ mice are not paralleled by haemorrhages, suggesting small BBB disruptions. a Intraperitoneal injection of late-stage TG mice and their $\operatorname{arcA} \beta$ NTG littermates with Trypan Blue showed extravasations of Trypan blue mainly around small vessels in the TG animals (asterisks). Bigger arterioles (a, plus sign) and arteries (a, arrow) were found to accumulate Trypan Blue within the vessel wall. Both small vessel extravasation and arterial accumulation of Trypan Blue within the vessel wall was only seen for vessels affected

in $\operatorname{AD}[3,50]$. The impaired lactate release we observed upon in vivo neuronal stimulation during microdialysis in TG $\operatorname{arc} \mathrm{A} \beta$ mice, was confirmed by a decreased astrocytic MCT1 expression and lactate release deficiency ex vivo. The reciprocal character of the expression profiles of MCT1 and GLUT1 as shown by Maurer and colleagues [33] makes plausible that the decreased astrocytic MCT1 protein levels could be related to lower astrocytic GLUT1.

by CAA. Scale bar a $150 \mu \mathrm{m}$. Hue settings of fluorescence for Trypan Blue were altered for more contrast effect explaining the blue colour. (b) Thioflavin S staining (green-yellow) combined with Prussian Blue staining (dark blue, asterisk) showed CAA-related presence of haemorrhages. Scale bar b $30 \mu \mathrm{m}$. The number of haemorrhages was significantly lower than Trypan Blue extravasations (c) and not chronically paralleled by vascular casting resin protrusions (d). Scale bar d $150 \mu \mathrm{m}$

Astrocytic GLUT1 and MCT1 are mainly expressed on astrocyte endfeet which are crucial for neurovascular coupling [1, 3, 65]. Impaired neurovascular coupling is common in neurodegenerative disorders including $\mathrm{AD}$ and $\mathrm{AD}$ mouse models with astrocyte endfeet retraction and swelling compromising the cross-talk between astrocytes, blood vessels and neurons and decreased cerebral metabolism as histological and functional hallmarks [3, 37, 61]. 

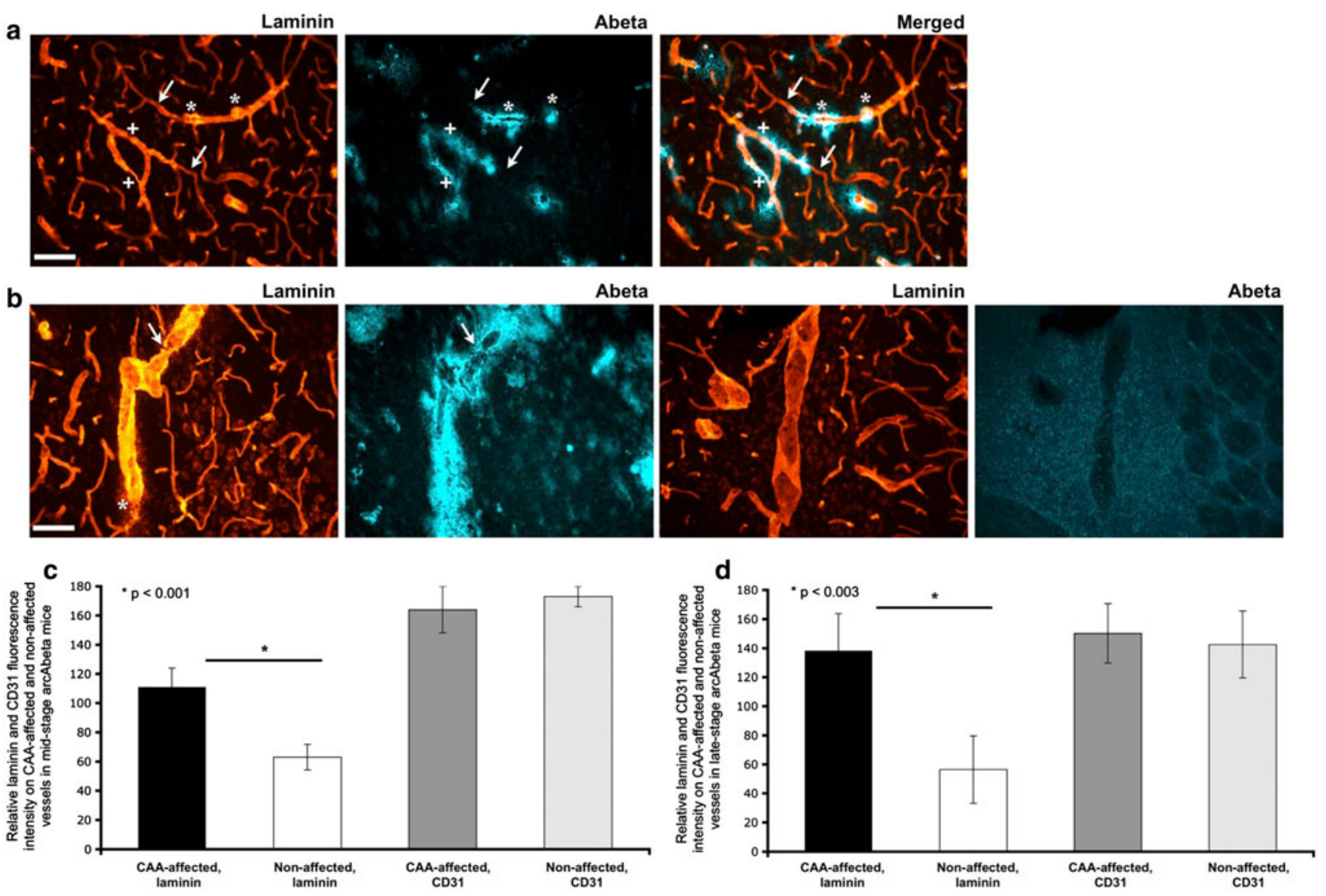

Fig. 10 Vascular basement membrane abnormalities in mid and latestage TG $\operatorname{arcA} \beta$ mice. Constrictions/stenoses (a, plus signs) and localised thickening of the vessel walls (a, asterisks) were abundantly seen on CAA-laden vessels in brains of late-stage TG $\operatorname{arc} \mathrm{A} \beta$ mice. These basement membrane irregularities due to laminin over-expression (a) were confined to those parts of the cerebral vessels that were affected by CAA; all other parts showed normal laminin expression and smooth vessel wall appearance (a, arrows). Severe CAA in latestage TG arcA $\beta$ mice (b) caused both intense and significant increase

in laminin immunopositivity and rupture of the vascular basement membrane laminin (b, arrow; $\mathbf{c}$ and $\mathbf{d})$. In addition, dust-like laminin particles could be observed surrounding the affected vessel (b, asterisk). Cerebral vessels of arcA $\beta$ NTG littermates lacked CAA and vascular basement membranes showed typical laminin immunopositivity (b, last two image sets). Scale bar a $150 \mu \mathrm{m}$; b $30 \mu \mathrm{m}$. Hue settings of fluorescence for $A \beta$ were altered for more contrast effect explaining the blue colour

We detected signs of neurovascular uncoupling represented by astrocyte endfeet retraction and swelling, possibly also (partly) explaining our findings on impaired metabolism. We observed this starting at an early pathological stage of the disease, at which extracellular $A \beta$ plaque burden is small in the $\operatorname{arc} A \beta$ mouse. Only astrocytes surrounding diffuse $A \beta$ plaques and vascular $A \beta$ deposits showed endfeet abnormalities even at the late-stage pathology, suggesting that $A \beta$ instigates the loss of neurovascular coupling rather than the process of ageing or the mere presence of the APP transgene in these mice. The mechanism by which $A \beta$ prevents contact between endfeet could be the formation of a physical barrier between blood vessels and astrocytes. Another likely mechanism underlying this impaired astrocyte-endothelium interaction could be the loss of expression of the astrocyte endfeet-VBM linker $\beta$ dystroglycan as we observed in our TG $\operatorname{arcA} \beta$

mice $[2,53]$. It is unclear whether $A \beta$ toxicity is involved in the attenuated $\beta$ dystroglycan expression or that the changes in the VBM we describe here and were described by others [21] are culprit. Interestingly, however, the degree of $\beta$ dystroglycan loss was paralleled by the presence of diffuse, parenchymal $A \beta$ plaques and leakage of endogenous IgG into the brain. Astrocyte endfeet form an essential part of the BBB [1] and the question is if detachment of astrocyte endfeet from the vasculature leading to disruption of the BBB and hence extravasation of serum proteins into the CNS or that entry of serum proteins into the brain is responsible for this aspect of neurovascular uncoupling. Brains of multiple sclerosis patients and its in vivo counterpart experimental autoimmune encephalomyelitis show that neuroinflammation and extravasation of components of the peripheral immune system induce astrocyte endfeet abnormalities including 
Fig. 11 Vascular smooth muscle cells are degenerated and severely affected in CAAladen cerebral vessels in latestage TG arc $\mathrm{A} \beta$ mice. CAAladen arteries and arterioles in late-stage $\mathrm{TG} \operatorname{arcA} \beta$ mice showed a characteristic thickening of the laminin basement membrane (a, upper arrows) and dust-like laminin particles were regularly observed (a, lower arrow). Vascular SMC layers were severely degenerated or completely absent (a, asterisk and arrows; c). In contrast, NTG littermates were found to have a typical laminin basement membrane thickness (b) and an intact, uninterrupted vascular SMC stratum (b, arrow and asterisk). Plus signs in a show presence of mouse $\operatorname{IgG}$ which was detected by the same secondary anti-mouse antibody (FITC-tagged donkey antimouse $\operatorname{IgG}$ ) used to visualise primary anti-smooth muscle actin antibody which was raised in mouse, explaining the presence of both smooth muscle cell and endogenous mouse $\operatorname{IgG}$ on the same brain sections. Scale bar a $150 \mu \mathrm{m}$
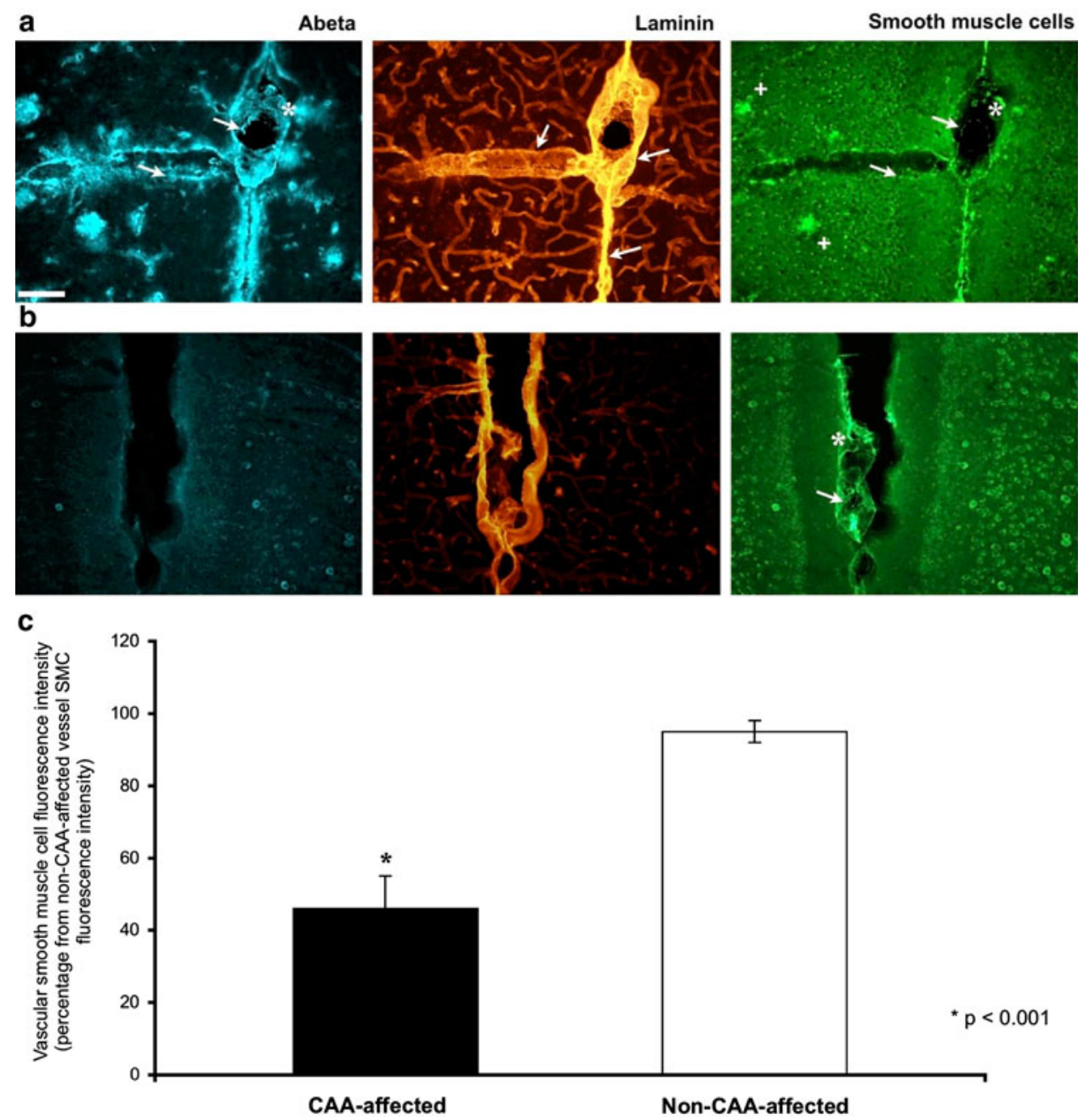

retraction and swelling [2, 63]. It is well established that CNS entry of components of the peripheral immune system is part of the $\mathrm{AD}$ pathology [13]. Taking into account our findings on the pathological cerebral extravasation of the BBB viability marker Trypan Blue and vessel wall instability as shown by leakage of vascular casting resin in the $\mathrm{TG} \operatorname{arcA} \beta$ mice, a role for components of the peripheral immune system in (further) triggering pathological astrocyte responses including endfeet retraction could indeed be possible $[1,13,65]$. It is clear that with astrocyte endfeet abnormalities already present at the early-stage pathology, impaired $\mathrm{BBB}$ functioning is a premature process in the $\operatorname{arc} A \beta$ mouse. An astrocytic involvement at premature time points in the pathology was further indicated by astrogliosis with paralleled increase in vascular laminin and astrocytic laminin secretion ex vivo in the early-stage mice. Increase in laminin VBM in these relatively young mice with little $A \beta$ plaque burden seems to be contradictory with the unique CAA-related increase in laminin we found in mid-stage and late-stage mice. It is interesting, however, that mainly the incoming arteries from leptomeningeal origin showed this increased astrocyte activation in the early-stage TG mice with concomitant increase in VBM laminin. It is exactly these vessels which are the first to be affected by CAA at later disease stages in the $\operatorname{arcA} \beta$ mouse and other transgenic $\mathrm{AD}$ mouse models [58, 59]. The induction of signal transduction cascades within the endothelium can trigger astrocytic release of endotheliumprotective molecules [1]. This protective reaction could be elicited by soluble $A \beta$ species which are known to induce astrocyte activation and to be toxic to endothelial cells and SMCs $[18,51,56,60]$. Furthermore, laminin expression is known to be up-regulated by damage to the vasculature $[4$, 65]. Soluble $A \beta$ species mainly as toxic protofibrils are abundantly present in $\operatorname{arc} \mathrm{A} \beta$ mice from 2 months of age onwards $[31,35]$ and could be directed to the vasculature by the forces of the cerebrovascular drainage pathways in which especially the cerebral arteries are involved [9, 20, 58], providing a possible explanation for the unique location of these reactive astrocytes around blood vessels. Seen in this light, laminin is known to interact with $\mathrm{A} \beta$, inhibiting its fibrillisation and diluting its neurotoxicity $[27,36]$, 
giving foundation to the idea that astrocytic laminin release as we detected could be a protective mechanism to both strengthen the vessel wall by increasing VBM thickness and an attempt to reduce $\mathrm{A} \beta$-induced neuro- and vascular toxicity by interfering with (further) $A \beta$ fibrillisation. Although we found astrocytes to secrete laminin as was observed by others as well $[8,45]$, it cannot be excluded that endothelial cells themselves are involved too as these cells can secrete laminin [19]. Although possibly being an astrocytic protection attempt, an increase in laminin secretion paralleled by VBM thickening leads to vessel wall rigidity and hence reduced $\mathrm{CBF}$, especially the leptomeningeal vessel wall thickening we observed in earlystage TG arcA $\beta$ mice which directly affects downstream perfusion of the arterioles and capillaries [23, 30]. Cerebral hypoperfusion - and with that reduced oxygen and glucose supply and hindered cerebral drainage of cerebral waste products-starting at such early age could be at the base of the accumulation of $A \beta$ and the severe CAA-related vascular pathology with vascular SMC loss and BBB impairments as we observed later on at mid- and late-stage pathology in the $\operatorname{arc} \mathrm{A} \beta$ mice.

Together, our data underscore the role of the impaired brain vascular system accompanying $\beta$-amyloid pathology $[4,7,17,59,64]$ and they establish that astrocytes are already involved early on in the disease in $\operatorname{arcA} \beta$ mice, with further age-related progression in severity. Further, our data suggest that impaired functions of astrocytes related to cerebral energy deficits may contribute to decreased neuronal and vascular functions followed later by pathological stages of $\beta$-amyloid pathology in $\operatorname{arc} \mathrm{A} \beta$ mice.

Acknowledgments We thank Drs. Antonella Chadha-Santuccione and Zoë Goodger for careful reading of the manuscript and Daniel Schuppli for breeding and caretaking of the $\operatorname{arcA} \beta$ mice. This work was funded by the Swiss National Science Foundation SNSF, grant number 3200B0-112616/1, and the National Centre of Competence in Research NCCR "Neural Plasticity and Repair”, project 2.

Conflict of interest The authors declare that they have no conflict of interest.

Open Access This article is distributed under the terms of the Creative Commons Attribution Noncommercial License which permits any noncommercial use, distribution, and reproduction in any medium, provided the original author(s) and source are credited.

\section{References}

1. Abbott NJ, Rönnbäck L, Hansson E (2006) Astrocyte-endothelial interactions at the blood-brain barrier. Nat Rev Neurosci 7:41-53

2. Agrawal S, Anderson P, Durbeej M et al (2006) Dystroglycan is selectively cleaved at the parenchymal basement membrane at sites of leukocyte extravasation in experimental autoimmune encephalomyelitis. J Exp Med 203:1007-1019

3. Allaman I, Bélanger M, Magistretti PJ (2011) Astrocyte-neuron metabolic relationships: for better and for worse. Trends Neurosci 34:76-87

4. Bell RD, Zlokovic BV (2009) Neurovascular mechanisms and blood-brain barrier disorder in Alzheimer's disease. Acta Neuropathol 118:103-113

5. Bourasset F, Ouellet M, Tremblay C et al (2009) Reduction of the cerebrovascular volume in a transgenic mouse model of Alzheimer's disease. Neuropharmacology 56:808-813

6. Bruno Solerte S, Ferrari E, Cuzzoni G et al (2005) Decreased release of the angiogenic peptide vascular endothelial growth factor in Alzheimer's disease: recovering effect with insulin and DHEA sulfate. Karg Demen Ger Cog Dis 19:1-10

7. Castellani RJ, Smith MA, Perry G, Friedland RP (2004) Cerebral amyloid angiopathy: major contributor or decorative response to Alzheimer's disease pathogenesis. Neurobiol Aging 25:599-602

8. Chiu AY, Espinosa De Los Monteros E, Cole RA, Loera S, De Vellis J (1991) Laminin and s-laminin are produced and released by astrocytes, Schwann cells and schwannomas in culture. Glia 4:11-24

9. Crawford F, Soto C, Suo Z et al (1998) Alzheimer's $\beta$-amyloid vasoactivity: identification of a novel $\beta$-amyloid conformational intermediate. FEBS Lett 436:445-448

10. Dai W, Lopez OL, Carmichael OT, Becket JT, Kuller LH, Gach HM (2009) Mild cognitive impairment and Alzheimer disease: patterns of altered cerebral blood flow at MR imaging. Radiology 250:856-866

11. de la Torre JC (2010) The vascular hypothesis of Alzheimer's disease: bench to bedside and beyond. Karg Neurodeg Dis 7:116-121

12. Desgranges B, Baron JC, de la Sayette V et al (1998) The neural substrates of memory systems impairment in Alzheimer's disease. A PET study of resting brain glucose utilisation. Brain 121:611-631

13. Diamond B, Huerta PT, Mina-Osorio P, Czeslawa K, Volpe BT (2009) Losing your nerves? Maybe it's the antibodies. Nat Rev Immunol 9:449-456

14. Dienel GA, Hertz L (2001) Glucose and lactate metabolism during brain activation. J Neurosci Res 66:824-838

15. Farkas E, Luiten PGM (2001) Cerebral microvascular pathology in aging and Alzheimer's disease. Prog Neurobiol 64:575-611

16. Fossati S, Cam J, Meyerson J et al (2010) Differential activation of mitochondrial apoptotic pathways by vasculotropic amyloid- $\beta$ variants in cells composing the cerebral vessel walls. FASEB $\mathbf{J}$ 24:229-241

17. Frackowiak J, Potempska A, Mazur-Kolecka B (2009) Formation of amyloid- $\beta$ oligomers in brain vascular smooth muscle cells transiently exposed to iron-induced oxidative stress. Acta Neuropathol 117:557-567

18. Frackowiak J, Zoltowska A, Wisniewski HM (1994) Non-fibrillar beta-amyloid protein is associated with smooth muscle cells of vessel walls in Alzheimer disease. J Neuropathol Exp Neurol 53:637-645

19. Gospodarowicz D, Greenburg G, Foidart JM, Savion N (2005) The production and localization of laminin in cultured vascular and corneal endothelial cells. J Cell Physiol 107:171-183

20. Hadaczek P, Yamashita Y, Mirek H et al (2006) The "perivascular pump" driven by arterial pulsation is a powerful mechanism for the distribution of therapeutic molecules within the brain. Mol Ther 14:69-78

21. Hayden MR, Sowers JR, Tyagi SC (2005) The central role of vascular extracellular matrix and basement membrane remodeling in metabolic syndrome and type 2 diabetes: the matrix preloaded. BMC Cardiovasc Diabetol 28:9 
22. Hooijmans CR, Graven C, Dederen PJ, Tanila H, van Groen T, Kiliaan AJ (2007) Amyloid beta deposition is related to decreased glucose transporter-1 levels and hippocampal atrophy in brains of aged APP/PS1 mice. Brain Res 1181:93-103

23. Iadecola C, Nedergaard M (2007) Glial regulation of the cerebral microvasculature. Nat Neurosci 10:1369-1376

24. Kalaria RN (2009) Linking cerebrovascular defense mechanisms in brain ageing and Alzheimer's disease. Neurobiol Aging 30:1512-1514

25. Kalaria RN (2009) Neurodegenerative disease: diabetes, microvascular pathology and Alzheimer disease. Nat Rev Neurol 5:305-306

26. Kalaria RN, Harik SI (1989) Reduced glucose transporter at the blood-brain barrier and in cerebral cortex in Alzheimer's disease. J Neurochem 53:1083-1088

27. Kasai S, Urushibata S, Hozumi K et al (2007) Identification of multiple amyloidogenic sequences in laminin-1. Biochemistry 46:3966-3974

28. Knobloch M, Konietzko U, Krebs DC, Nitsch RM (2007) Intracellular $A \beta$ and cognitive deficits precede $\beta$-amyloid deposition in transgenic arcA $\beta$ mice. Neurobiol Aging 28:1297-1306

29. Kuhr WG, Korf J (1988) Extracellular lactic acid as an indicator of brain metabolism: continuous on-line measurement in conscious, freely moving rats with intrastriatal microdialysis. J Cereb Blood Flow Metab 8:130-137

30. Kumar-Singh S (2009) Hereditary and sporadic forms of A $\beta$ cerebrovascular amyloidosis and relevant transgenic mouse models. Internat J Mol Sci 10:1872-1895

31. Lord A, Englund H, Söderberg L et al (2009) Amyloid $\beta$ protofibril levels correlate with spatial learning in Arctic Alzheimer's disease transgenic mice. FEBS J 276:995-1006

32. Maekawa F, Minehira K, Kadomatsu K, Pellerin L (2008) Basal and stimulated lactate fluxes in primary cultures of astrocytes are differentially controlled by distinct proteins. J Neurochem 107:789-798

33. Maurer MH, Canis M, Kuschinsky W, Duelli R (2004) Correlation between local monocarboxylate transporter 1 (MCT1) and glucose transporter 1 (GLUT1) densities in the adult rat brain. Neurosci Lett 355:105-108

34. Meyer EP, Ulmann-Schuler A, Staufenbiel M, Krucker T (2008) Altered morphology and 3D architecture of brain vasculature in a mouse model for Alzheimer's disease. Proc Natl Acad Sci USA 105:3587-3592

35. Nilsberth C, Westlind-Danielsson A, Eckman CB et al (2001) The "Arctic" APP mutation (E693G) causes Alzheimer's disease by enhanced A $\beta$ protofibril formation. Nat Neurosci 4:887-893

36. Palu E, Liesi P (2002) Differential distribution of laminins in Alzheimer disease and normal human brain tissue. J Neurosci Res 69:243-256

37. Pellerin L (2005) How astrocytes feed hungry neurons. Mol Neurobiol 32:59-72

38. Pellerin L, Magistretti PJ (1994) Glutamate uptake into astrocytes stimulates aerobic glycolysis: a mechanism coupling neuronal activity to glucose utilisation. Proc Natl Acad Sci USA 91:10625-10629

39. Persson L, Hansson H-A, Sourander P (1976) Extravasation, spread and cellular uptake of Evans blue-labelled albumin around a reproducible small stab-wound in the rat brain. Acta Neuropathol 34:125-136

40. Pezzini A, Del Zotto E, Volonghi I, Giossi A, Costa P, Padovani A (2009) Cerebral amyloid angiopathy: a common cause of cerebral hemorrhage. Curr Med Chem 16:2498-2513

41. Pierre K, Pellerin L, Debernardi R, Riederer BM, Magistretti PJ (2000) Cell-specific localisation of monocarboxylate transporters, MCT1 and MCT2, in the adult mouse brain revealed by double immunohistochemical labeling and confocal microscopy. Neuroscience 100:617-627

42. Rönnbäck A, Zhu S, Dillner K et al (2011) Progressive neuropathology and cognitive decline in a single Arctic APP transgenic mouse model. Neurobiol Aging 32:280-292

43. Schurr A, Miller JJ, Payne RS, Rigor BM (1999) An increase in lactate output by brain tissue serves to meet the energy needs of glutamate-activated neurons. J Neurosci 19:34-39

44. Schurr A (2006) Lactate: the ultimate cerebral oxidative energy substrate? J Cereb Blood Flow Metab 26:142-152

45. PhDTB Shea, Beerman ML, Honda T, Nixon RA (1993) Secretion of amyloid precursor protein and laminin by cultured astrocytes is influenced by culture conditions. J Neurosci Res 37:197-207

46. Simpson IA, Carruthers A, Vannucci SJ (2007) Supply and demand in cerebral metabolism: the role of nutrient transporters. J Cereb Blood Flow Metab 27:1766-1791

47. Simpson IA, Chundu KR, Davies-Hill T, Honer WG, Davies P (1994) Decreased concentrations of GLUT1 and GLUT3 glucose transporters in the brains of patients with Alzheimer's disease. Ann Neurol 35:546-551

48. Simpson JE, Ince PG, Lace G et al (2010) Astrocyte phenotype in relation to Alzheimer-type pathology in the ageing brain. Neurobiol Aging 31:578-590

49. Smith EE, Greenberg SM (2009) $\beta$-amyloid, blood vessels, and brain function. Stroke 40:2601-2606

50. Steele ML, Robinson SR (2010) Reactive astrocytes give neurons less support: implications for Alzheimer's disease. Neurobiol Aging (in press)

51. Suhara T, Magrané J, Rosen K et al (2003) Abeta42 generation is toxic to endothelial cells and inhibits eNOS function through an Akt/GSK-3beta signalling-dependent mechanism. Neurobiol Aging 24:437-451

52. Thal DR, Griffin WST, de Vos RAI, Ghebremedhin E (2008) Cerebral amyloid angiopathy and its relationship to Alzheimer's disease. Acta Neuropathol 115:599-609

53. Tian M, Jacobson C, Gee SH, Campbell KP, Carbonetto S, Jucker M (1996) Dystroglycan in the cerebellum is a laminin $\alpha 2$-chain binding protein at the glial-vascular interface and is expressed in Purkinje cells. Eur J Neurosci 8:2739-2747

54. Vagnucci AH Jr, Li DW (2003) Alzheimer's disease and angiogenesis. Lancet 361:605-608

55. Van Dorpe J, Smeijers L, Dewachter I et al (2000) Prominent cerebral amyloid angiopathy in transgenic mice overexpressing the London mutant of human APP in neurons. Am J Pathol 157:1283-1298

56. Wang DD, Bordey A (2008) The astrocyte odyssey. Prog Neurobiol 86:342-367

57. Weller RO, Boche D, Nicoll JAR (2009) Microvasculature changes and cerebral amyloid angiopathy in Alzheimer's disease and their potential impact on therapy. Acta Neuropathol 118:87-102

58. Weller RO, Massey A, Newman TA, Hutchings M, Kuo Y-M, Roher AE (1998) Amyloid beta accumulates in putative interstitial fluid drainage pathways in Alzheimer's disease. Am J Pathol 153:725-733

59. Weller RO, Preston SD, Subash M, Carare RO (2009) Cerebral amyloid angiopathy in the aetiology and immunotherapy of Alzheimer disease. Alz Res Ther 1:6

60. White JA, Manelli AM, Holmberg KH, Van Eldik LJ, LaDu MJ (2005) Differential effects of oligomeric and fibrillar amyloid- $\beta 1$ 42 on astrocyte mediated inflammation. Neurobiol Dis $18: 459-465$

61. Wilcock DM, Vitek MP, Colton CA (2009) Vascular amyloid alters astrocytic water and potassium channels in mouse models 
and humans with Alzheimer's disease. Neuroscience 159:10551069

62. Winkler DT, Bondolfi L, Herzig MC et al (2001) Spontaneous hemorrhagic stroke in a mouse model of cerebral amyloid angiopathy. J Neurosci 21:1619-1927

63. Wolburg-Buchholz K, Mack AF, Steiner E, Pfeiffer F, Engelhardt B, Wolburg H (2009) Loss of astrocyte polarity marks blood- brain barrier impairment during experimental autoimmune encephalomyelitis. Acta Neuropathol 118:219-233

64. Zlokovic BV (2005) Neurovascular mechanisms of Alzheimer's neurodegeneration. Trends Neurosci 28:202-208

65. Zlokovic BV (2008) The blood-brain barrier in health and chronic neurodegenerative disorders. Neuron 57:178-201 